Geosci. Model Dev. Discuss., doi:10.5194/gmd-2016-213, 2016

Manuscript under review for journal Geosci. Model Dev.

Published: 8 November 2016

(c) Author(s) 2016. CC-BY 3.0 License.

\title{
Description and evaluation of REFIST v1.0: a regional greenhouse gas flux inversion system in Canada
}

Elton Chan ${ }^{1}$, Douglas Chan ${ }^{1}$, Misa Ishizawa ${ }^{2},{\text { Felix } \text { Vogel }^{3}, \text { Jerome Brioude }^{4} \text {, Andy Delcloo }}^{5}$, Yuehua $\mathrm{Wu}^{6}$, Baisuo $\mathrm{Jin}^{7}$

${ }^{1}$ Climate Research Division, Environment and Climate Change Canada, Toronto, Ontario, Canada

Correspondence to: Elton Chan (elton.chan@ canada.ca)

${ }^{2}$ Center for Global Environmental Research, National Institute for Environmental Studies, Tsukuba, Japan

${ }^{3}$ Laboratoire des Sciences du Climat et de l'Environnement, Chaire BridGES, Gif-sur-Yvette, France

${ }^{4}$ Laboratoire de l'Atmosphere et des Cyclones, UMR8105, CNRS-Meteo France-Universite La Reunion, La Reunion,

France

${ }^{5}$ Royal Meteorological Institute of Belgium, Uccle, Belgium

${ }^{6}$ Mathematics and Statistics, York University, Toronto, Ontario, Canada

${ }^{7}$ Statistics and Finance, University of Science and Technology of China, Hefei, Anhui, China 
Geosci. Model Dev. Discuss., doi:10.5194/gmd-2016-213, 2016

Manuscript under review for journal Geosci. Model Dev.

Published: 8 November 2016

(c) Author(s) 2016. CC-BY 3.0 License.

Abstract

A regional greenhouse gas flux inversion system (REFIST v1.0) is described. This paper

3 provides a comprehensive evaluation of REFIST for three provinces in Canada that include

4 Alberta (AB), Saskatchewan (SK) and Ontario (ON). Using year 2009 fossil fuel $\mathrm{CO}_{2}$

5 CarbonTracker model results as the target, the synthetic data experiment analyses examined the

6 impacts of the errors from the Bayesian optimisation method, inversion time span, prior flux

7 distribution, region definition and the atmospheric transport model, as well as their interactions.

8 The posterior fluxes were estimated by two different optimisation methods, the Markov chain

9 Monte Carlo (MCMC) simulation and cost function minimization (CFM) methods. Increasing the

10 number of sub-regions (unknowns) beyond "optimality" can produce unstable and unrealistic

11 fluxes for some sub-regions, and does not yield significantly different flux estimates overall. The

12 two optimisation methods can provide comparable, stable and realistic flux results when the

13 transport model error is small (prior $\mathrm{R}^{2} \sim 0.8$ with synthetic observations), but both methods

14 present difficulty when the transport model error is large (prior $\mathrm{R}^{2} \sim 0.3$ ). Stable and realistic sub-

15 regional and monthly flux estimates for the western region of $\mathrm{AB}+\mathrm{SK}$ can be obtained, but not

16 for the eastern region of $\mathrm{ON}$ without excluding a poorly simulated station. This indicates a real

17 observation-based inversion will likely work for the western region for tracers with similar

18 temporal and spatial emission characteristics to fossil fuel $\mathrm{CO}_{2}$ [e.g. wintertime $\mathrm{CH}_{4}$ in Canada].

19 However, improvements are needed with the current inversion setup before a real inversion is

20 performed for the eastern region. 
Geosci. Model Dev. Discuss., doi:10.5194/gmd-2016-213, 2016

Manuscript under review for journal Geosci. Model Dev.

Published: 8 November 2016

(c) Author(s) 2016. CC-BY 3.0 License.

\section{Introduction}

Continental continuous measurements are useful for understanding and quantifying the

Bayesian inversion approach for atmospheric applications that incorporates prior fluxes and their associated first guess uncertainties was applied to $\mathrm{CO}_{2}$ in Enting et al. $(1993,1995)$ and Fan et al. $(1998,1999)$. Since then a large number of atmospheric GHG inversion studies spanning over the last two decades have estimated GHG sources and sinks globally including CarbonTracker $\mathrm{CO}_{2}$ (Peters et al., 2007), CarbonTracker $\mathrm{CH}_{4}$ (Bruhwiler et al., 2014) and TransCom3 (Gurney et al., 2002). Regionally there have been many inverse modelling studies focusing on Europe (e.g. Bergamaschi et al., 2005, 2010; Stohl et al., 2009; Manning et al., 2011; Rigby et al., 2011; Thompson et al., 2011; Tolk et al., 2011; Cressot et al., 2014) and the U.S. (e.g. Zhao et al., 2009; Jeong et al., 2012; Brioude et al., 2011, 2012, 2013; Miller et al., 2013; Gerbig et al., 2003; Kort et al., 2008). Large discrepancies were found in the flux estimates and spatial distributions among studies (e.g. Vogel et al., 2012; Miller et al., 2013), reflecting the 
Geosci. Model Dev. Discuss., doi:10.5194/gmd-2016-213, 2016

Manuscript under review for journal Geosci. Model Dev.

Published: 8 November 2016

(c) Author(s) 2016. CC-BY 3.0 License.

differences in the modelling approaches (e.g. different atmospheric transports, optimization methods, etc.) and assumptions (e.g. different prior fluxes and uncertainties, domain definitions, etc.).

Miller et al. (2014) compared a number of Bayesian models optimized by the cost function minimization method (CFM) and the Markov chain Monte Carlo (MCMC) method. The conclusion was that the MCMC estimation method produced the most realistic estimates and confidence intervals with known bounds. They pointed out inverse modelling approaches based on Gaussian assumptions could not incorporate such bounds and often produced unrealistic results. For example, emission grids or regions may have known physical constraints (e.g. nonnegative emissions). Similarly, in Brioude et al (2011), an improvement of the cost function method was introduced by using an iterative method to find the median of the posterior distribution instead of the mean. When positive (net) fluxes were expected, their method was not required to impose any non-negativity constraints on the covariance matrices to ensure positive flux results.

It is important to point out that many studies applied Gaussian noise to the synthetic observations to simulate transport model errors in their sensitivity tests (Stohl et al., 2009; Gourdji et al., 2010; Thompson et al., 2011; Miller et al., 2014 and Ganesan et al., 2014). Thus, when the performance of inversion approaches was compared, the impact of the transport model error and bias on the inverse estimates was not fully examined.

The sources of uncertainties in any inverse models should be studied systematically with synthetic data experiments with known fluxes before applying to real observations. This is the 
Geosci. Model Dev. Discuss., doi:10.5194/gmd-2016-213, 2016

Manuscript under review for journal Geosci. Model Dev.

Published: 8 November 2016

(c) Author(s) 2016. CC-BY 3.0 License.

motivation for this study in which we assess our inverse modelling approach using different setups and inversion domains. We characterize the sensitivity and limitations of the various components of the inverse model using a series of synthetic observation experiments that allow us to investigate the impacts associated with individual and combined errors.

(4)

$$
\text { We evaluated our inversion setup starting with a target flux distribution that is slowly }
$$
varying and positive definite (source only). A suitable choice of target is CarbonTracker fossil fuel $\mathrm{CO}_{2}$ which varies on the monthly timescale. Using CarbonTracker fossil fuel $\mathrm{CO}_{2}$ model results with monthly fluxes as the target synthetic observations, we report here on the inversion estimation errors introduced by the prior flux errors, atmospheric transport model errors, optimisation schemes, the sensitivity to the number of source regions optimised, as well as combinations of these sources of errors. This study can provide insights for regional flux estimations for tracers that have similar temporal and spatial emission characteristics to fossil fuel $\mathrm{CO}_{2}$ [e.g. wintertime $\mathrm{CH}_{4}$ in Canada with mainly anthropogenic sources (fossil fuel, agriculture and waste or landfill) and essentially no wetland emissions]. Other tracers such as $\mathrm{N}_{2} \mathrm{O}$ and $\mathrm{SF}_{6}$ which are predominately contributed from the anthropogenic sources with small seasonality can potentially be used for flux inversion following the methodology developed in this study.

$$
\text { The term "posterior error" will be used wherever appropriate throughout the text to }
$$
represent the estimation error [relative percentage difference of the posterior flux and the target flux, i.e. (posterior flux - target flux)/target flux) x 100\%]. The contributions and the interaction of the different error components including the errors of the inversion procedure, prior flux and transport model are examined using sensitivity experiments. However, in the real observationsbased inversion, the magnitude and sign of the errors are often not known and often treated as 
Geosci. Model Dev. Discuss., doi:10.5194/gmd-2016-213, 2016

Manuscript under review for journal Geosci. Model Dev.

Published: 8 November 2016

(c) Author(s) 2016. CC-BY 3.0 License.

part of the total estimation uncertainty. This study will show that uncertainty of the flux estimates could often be unrealistically small. The sensitivity of the estimation error (when the truth is known in synthetic experiments) and uncertainty (when the truth is not known in reality) needs to be closely examined in any inversion setup.

\section{Methods}

In this study, the components of atmospheric inversion include 1) the synthetic observations (target), 2) a Lagrangian particle dispersion model (LPDM) run in backward (adjoint) mode, 3) assimilated meteorological fields used to drive the LPDM, 4) prior spatial distributions of emissions, 5) a method to estimate the baseline (background influence) of the observations, and 6) a statistical technique to minimize any differences between prior and target mole fractions. The observed atmospheric $\mathrm{CO}_{2}$ mole fractions were not used, instead, synthetic observations (no land/ocean sink and no biospheric contributions) were simulated from monthly fossil fuel $\mathrm{CO}_{2}$ fluxes that were extracted from the outputs of the global model NOAA CarbonTracker release version 2011 (CT2011). Figure 1 shows a schematic of one set (III) of inversion experiments. The impacts of the components to the flux estimates as highlighted in gray boxes are the focus of this study. The details are described in the following sub-sections.

\subsection{Observation stations and inversion domains}

Seven existing surface GHG monitoring stations were selected as a test bed for evaluating the inverse modelling approach. These seven GHG stations summarized in Table 1 are located in the three Canadian provinces of Alberta, Saskatchewan and Ontario that together account for 
Geosci. Model Dev. Discuss., doi:10.5194/gmd-2016-213, 2016

Manuscript under review for journal Geosci. Model Dev.

Published: 8 November 2016

(c) Author(s) 2016. CC-BY 3.0 License.

115 close to $70 \%$ of Canada's total GHG emissions annually (ECCC, 2015). In 2013, $\mathrm{CO}_{2}$

116 contributed $78 \%$ (and $\mathrm{CH}_{4}$ contributed 15\%) of the national total GHG emissions of 726

117 megatonnes (Mt) of $\mathrm{CO}_{2}$ equivalent (ECCC, 2015). The majority of Canada's national total

118 anthropogenic GHG emissions resulted from the combustion of fossil fuels at about $80 \%$ and the

119 remaining portions were contributed from industrial processes, waste incinerations, agricultural

120 activities and landfills.

121

In this study, the inversion was done separately for the western region of Alberta and Saskatchewan provinces, and the eastern region of Ontario using seven region definitions as shown in Fig. 2a-g to investigate whether there are problems or benefits in estimating the fluxes from a large number of sub-regions.

\subsection{Prior fluxes}

Two sets of fossil fuel $\mathrm{CO}_{2}$ fluxes (CT2010 and CT2011 for year 2009) were used as prior and target (known "truth") fluxes and summarized in Table 2, which includes the monthly and annual provincial totals. The fluxes were uniformly re-distributed to $0.2^{\circ} \times 0.2^{\circ}$ from the original resolution of $1^{\circ} \mathrm{x} 1^{\circ}$ to be folded into the emission sensitivity fields from FLEXPART (next Section). For visualization, the gridded fluxes were aggregated into sub-regions as shown in Fig. 2. Year 2009 country and global totals (by fuel type) were extrapolated from the 2007 Carbon Dioxide Information Analysis Center (CDIAC, Boden et al. 2013) used for the CT2010 fossil fuel fluxes (CarbonTracker, 2010). Open-source Data Inventory for Anthropogenic $\mathrm{CO}_{2}$ (ODIAC, Oda and Maksyutov, 2011) emissions are spatially distributed using many available "proxy data" that explain spatial extent of emissions according to emission types (emissions over 
Geosci. Model Dev. Discuss., doi:10.5194/gmd-2016-213, 2016

Manuscript under review for journal Geosci. Model Dev.

Published: 8 November 2016

(c) Author(s) 2016. CC-BY 3.0 License. with CDIAC emissions to generate CT2011 fossil fuel fluxes (Andres et al., 2011, CarbonTracker, 2011).

The European Centre for Medium-range Weather Forecasts (ECMWF) operational wind fields at T799 spectral resolution were used to drive the Lagrangian particle dispersion model FLEXPART (Stohl et al., 2005). The ECMWF modelled data were retrieved with a temporal resolution of 3-h (analyses at 0000, 0600, 1200, and 1800 UTC; forecasts at 0300, 0900, 1500, and 2100 UTC) for two domains. The inner domain has a horizontal resolution of $0.2^{\circ} \mathrm{x} 0.2^{\circ}$ on the Gaussian grid over Canada and the US $\left(180^{\circ} \mathrm{W}\right.$ to $0^{\circ} \mathrm{E}$ and $20^{\circ} \mathrm{N}$ to $\left.90^{\circ} \mathrm{N}\right)$. The outer domain is a global grid with resolution of $1^{\circ} \times 1^{\circ}$. Both grids have 91 vertical levels. The FLEXPART model was used to simulate the 5-day transport history (retroplume) of the fossil fuel $\mathrm{CO}_{2}$ mole fractions at each station location. The model calculated the trajectories of 5,000 particles from the intake height at each station location daily at 21:00 UTC (14:00 to 16:00 LST depending on time zones) representing afternoon well-mixed condition near the surface. $\mathrm{x} 0.2^{\circ}$ grid. The retroplumes were then summed up for the entire 5 days for each time point (21:00 UTC daily) of particle release. The retroplume is the residence time of the plume per grid cell divided by the air density that has units of $\mathrm{s} \mathrm{kg}^{-1} \mathrm{~m}^{3}$. The footprint layer of the retroplume for FLEXPART is fixed at the standard 100 m layer adjacent to the Earth's surface (Stohl et al., 2005). The modelled fossil fuel $\mathrm{CO}_{2}$ mole fractions were constructed by multiplying the 
Geosci. Model Dev. Discuss., doi:10.5194/gmd-2016-213, 2016

Manuscript under review for journal Geosci. Model Dev.

Published: 8 November 2016

(c) Author(s) 2016. CC-BY 3.0 License.

retroplume distribution (footprint) with the monthly prior fossil fuel $\mathrm{CO}_{2}$ fluxes at $0.2^{\circ} \times 0.2^{\circ}$ in

$162 \mathrm{~kg} \mathrm{~s}^{-1}$ and summed up over all grid cells (plus the baseline or the contribution from prior to the 5-

163 day simulation period, described below) to yield the time series of modelled fossil fuel $\mathrm{CO}_{2}$ mole

164 fractions at the measurement station (Stohl et al., 2003, 2009; Cooper et al., 2010). The mean

165 footprint of the seven stations for January through December 2009 is shown in Fig. 3 to reveal

166 areas where the surface emissions can likely be constrained using the selected stations.

167

\subsection{Baseline estimations}

The station-specific baseline in this context represents the influence from emissions 5 days earlier and beyond. The mole fractions of the fossil fuel $\mathrm{CO}_{2}$ were sampled from the CT2011 predicted global fossil fuel $\mathrm{CO}_{2}$ field at the positions (latitude, longitude and altitude) of 5000 particles at the end of the $5^{\text {th }}$ day backward simulation for each station released at 21:00 UTC daily to obtain 5000 mole fraction values. These 5000 mole fractions were averaged to represent the mean baseline for each release time point. The station-specific baseline time series was subsequently subtracted from the synthetic observations that were sampled from CT2011 for each station. This allowed us to infer fluxes over the region of interest. Errors in the baseline estimation were treated as a part of the transport error when CT2011 mole fractions were used as the "target".

\subsection{Two Bayesian inversion methods}

In addition to the more common analytical-based CFM approach, we include a simulation-based method for flux estimations, MCMC. Sensitivity analyses of the two inversion 
Geosci. Model Dev. Discuss., doi:10.5194/gmd-2016-213, 2016

Manuscript under review for journal Geosci. Model Dev.

Published: 8 November 2016

(c) Author(s) 2016. CC-BY 3.0 License.

methods in terms of percentage differences between the posterior estimates and the target fossil

fuel $\mathrm{CO}_{2}$ fluxes are assessed. It is not the intention to compare which one of these two methods is

more superior to the other, but to evaluate the sensitivity of the results using different inversion methodologies and assumptions. quantities are in italic font. Inversion was done separately for the western and eastern domains, and separately for every three months of 2009 that is January-March, April-June, July-September and October-December. and time t. $x_{g, p, t}$ is the gridded emission field over sub-region $\mathrm{p}$ at time $\mathrm{t}$. The footprints vary in space, time and stations. The modelled mole fractions in our experiments were limited to 21:00 UTC daily (14:00 to 16:00 LST depending on time zones) in January through December for 2009 to avoid temporal correlation and night time processes. Two regions of interest are the two neighboring provinces of Alberta and Saskatchewan (western region), and separately, the province of Ontario (eastern region) in Canada. Any remaining contributions from outside of the inversion region but within the 5-day integration period were subtracted from the synthetic observations for each station in addition to the station-specific baseline time series. 
Geosci. Model Dev. Discuss., doi:10.5194/gmd-2016-213, 2016

Manuscript under review for journal Geosci. Model Dev.

Published: 8 November 2016

(c) Author(s) 2016. CC-BY 3.0 License.

\subsubsection{Simulation-based Markov-Chain Monte Carlo (MCMC) Method} regression model is shown below:

$$
y_{t, s}=\sum_{p \in R_{T}} \lambda_{p} \sum_{g \in G} M_{g, p, t, s} x_{g, p, t}+\epsilon_{t, s}
$$

for station $\mathrm{s}$, at time $\mathrm{t}$, scaling factors $\lambda_{p}$ for sub-region $\mathrm{p}$ to be estimated, $M_{g, p, t, s}$ is the stationspecific footprint to be summed up over the sub-region $\mathrm{p}$ for each footprint grid cell $\mathrm{g}$ with $\mathrm{G}$ being the total number of grid cells of sub-region p. $\epsilon_{t, s}$ are the residuals to be minimized. For a given time $t$ and station $s$, summing contributions from all sub-regions to the total number of $R_{T}$ sub-regions gives the total modelled mole fraction. Let $K_{p, t, s}=\sum_{g \in G} M_{g, p, t, s} x_{g, p, t}$ be the contribution from sub-region $\mathrm{p}$, for station $\mathrm{s}$ at time t. We obtain:

$$
y_{t, s}=\sum_{p \in R_{T}} \lambda_{p} K_{p, t, s}+\epsilon_{t, s}
$$

In the MCMC simulation method (Appendix), same prior error $\left(\sigma_{\text {prior }}\right)^{2}$ and prior model- 
Geosci. Model Dev. Discuss., doi:10.5194/gmd-2016-213, 2016

Manuscript under review for journal Geosci. Model Dev.

Published: 8 November 2016

(c) Author(s) 2016. CC-BY 3.0 License.

estimates are calculated by drawing samples from the joint distributions of the log likelihood and

the assumed distributions of prior parameters $\lambda_{\text {prior }}$ (briefly described below) instead of solving

for the parameters as in the analytical cost function method.

To implement the regression model as shown in Eq (1), we used the following Bayesian inversion settings for the western region and the eastern region. Assume $\lambda_{p}$ follows normal distribution with a mean of 1 and a variance of 1 for $\left(\sigma_{\text {prior }}\right)^{2}$, which corresponds to a $100 \%$ allowable error. In the MCMC method, $\left(\sigma_{e}\right)^{2}$ is assumed to follow inverse-gamma distribution, the mean and variance for $\left(\sigma_{e}\right)^{2}$ are prescribed by setting the shape and scale parameters to 2.1 and 1.1 respectively (Appendix). This gives a mean of 1 and a variance of 10 .

Sensitivity analysis was performed in the synthetic data experiments, in which the shape and scale parameters were changed to 2.001 and 1.001 respectively (not shown). This gives a mean of 1 and a variance of 1000 for the $\left(\sigma_{e}\right)^{2}$, which correspond to conjugate non-informative priors. Using non-informative priors allows MCMC to sample parameter estimates from a wide parameter space (Appendix). However, there were no significant differences in the results compared to the standard setting of 2.1 and 1.1 for the shape and scale parameters respectively that were used throughout this study.

In our MCMC method, a random-walk Metropolis algorithm (Appendix) (Roberts, 1996; Liu, 2001) was used to obtain posterior scaling factor estimates for the sub-regions. The $\lambda_{p}$ was initialized to 1, and each three-monthly inversion had 110,000 iterations (first 10,000 discarded 
Geosci. Model Dev. Discuss., doi:10.5194/gmd-2016-213, 2016

Manuscript under review for journal Geosci. Model Dev.

Published: 8 November 2016

(c) Author(s) 2016. CC-BY 3.0 License.

estimates is kept), the number of simulations saved for subsequent inferences was equal to 10,000

for three months. Although the use of mean posterior estimates should be avoided (Tarantola, 2005), it is necessary here to compare the results using MCMC to those using the CFM method.

Subsequently, the monthly posterior provincial total flux estimates were calculated using the posterior monthly fluxes.

$$
\begin{aligned}
& S_{A B}=\sum_{p=1}^{R_{A B}} \lambda_{p, A B} x_{p, A B} \\
& S_{S K}=\sum_{p=1}^{R_{S K}} \lambda_{p, S K} x_{p, S K} \\
& S_{O N}=\sum_{p=1}^{R_{O N}} \lambda_{p, O N} x_{p, O N}
\end{aligned}
$$

where $R_{A B}, R_{S K}$ and $R_{O N}$ are the total number of sub-regions for Alberta (AB), Saskatchewan

257
With large number of simulated scaling factors, various statistics on the posterior provincial fluxes can be calculated such as the percentiles, standard deviations and 95\% confidence intervals. 
Geosci. Model Dev. Discuss., doi:10.5194/gmd-2016-213, 2016

Manuscript under review for journal Geosci. Model Dev.

Published: 8 November 2016

(c) Author(s) 2016. CC-BY 3.0 License.

$$
J(\lambda)=(\boldsymbol{y}-K \boldsymbol{\lambda})^{T} \boldsymbol{D}_{\epsilon}^{-1}(\boldsymbol{y}-K \boldsymbol{\lambda})+\left(\boldsymbol{\lambda}-\lambda_{\text {prior }}\right)^{T} \boldsymbol{D}_{\text {prior }}^{-1}\left(\boldsymbol{\lambda}-\lambda_{\text {prior }}\right)
$$

271

272

273

274

275

276

277

278

279

280

281

282

283

284

285

286

where $\boldsymbol{y}(\mathrm{N} \times 1)$ is the vector of observations (synthetic observations). $\boldsymbol{\lambda}\left(\mathrm{R}_{\mathrm{T}} \times 1\right)$ is the vector of the posterior scaling factors to be estimated, $\mathrm{N}=$ number of time points times number of stations, $\mathrm{R}_{\mathrm{T}}=$ number of sub-regions in the inversion domain, $\lambda_{\text {prior }}$ is the vector of the prior scaling factors which are all initialized to 1 for all sub-regions and $\boldsymbol{K}\left(\mathrm{N} \mathrm{x} \mathrm{R}_{\mathrm{T}}\right)$ is the matrix of contributions from different sub-regions. $\boldsymbol{K}$ is the product of two matrices, $\boldsymbol{M}$ and $\boldsymbol{x} . \boldsymbol{M}$ is the modelled transport (or footprints in our case) and $\boldsymbol{x}$ is the spatial distribution of the surface emission fluxes. A linear regularization term has been added which is the second term on the right hand side of Eq. (4), a typical setup for undetermined (under-constrained due to lack of observations) problems such as atmospheric flux inversion. The LU decomposition procedure was used to compute $\lambda$ according to the expression below (Gerbig et al., 2003; Lin et al., 2004).

$$
\lambda=\left(\boldsymbol{K}^{T} \boldsymbol{D}_{\epsilon}^{-1} \boldsymbol{K}+\boldsymbol{D}_{\text {prior }}^{-1}\right)^{-\mathbf{1}}\left(\boldsymbol{K}^{T} \boldsymbol{D}_{\epsilon}^{-1} \boldsymbol{y}+\boldsymbol{D}_{\text {prior }}^{-\mathbf{1}} \lambda_{\text {prior }}\right)
$$
according to: 
Geosci. Model Dev. Discuss., doi:10.5194/gmd-2016-213, 2016

Manuscript under review for journal Geosci. Model Dev.

Published: 8 November 2016

(c) Author(s) 2016. CC-BY 3.0 License.

$$
\boldsymbol{\Sigma}_{\text {post }}=\left(\boldsymbol{K}^{T} \boldsymbol{D}_{\epsilon}^{-1} \boldsymbol{K}+\boldsymbol{D}_{\text {prior }}^{-1}\right)^{-1}
$$

287

288

The error covariance matrices are not known, consequently $\boldsymbol{D}_{\epsilon}$ and $\boldsymbol{D}_{\text {prior }}$ are assumed to be diagonal matrices following e.g. Gerbig et al., 2003; Stohl et al., 2009. $\boldsymbol{D}_{\epsilon}$ is the prior modelobservation error diagonal matrix with diagonal elements $\left(\sigma_{e}\right)^{2}$. Similarly, $\boldsymbol{D}_{\text {prior }}$ is the prior scaling factor diagonal matrix where the diagonal elements are $\left(\sigma_{\text {prior }}\right)^{2}$ and zeros everywhere else. For further simplification, same individual $\left(\sigma_{e}\right)^{2}$ scalar element in percentage is assigned to all measurement stations at all time points. Similarly, same individual $\left(\sigma_{\text {prior }}\right)^{2}$ in percentage is assigned to all sub-regions.

Note that the symbols of the individual elements of $y_{t, s}, \lambda_{p}, M_{g, p, t, s}, x_{g, p, t}, K_{p, t, s}$ for the MCMC method presented in Eqs. (1) and (2) are consistent with the matrix notations used in Eq. (4) $\boldsymbol{y}, \boldsymbol{\lambda}, \boldsymbol{M}, \boldsymbol{x}, \boldsymbol{K}$ for the CFM method.

\subsection{Synthetic Data Experiments}

To have a measure of the ability and limitations of the proposed inversion approaches, four components were examined in this study: 1) the magnitude and spatial distribution of the prior fluxes, 2) modelled transport, 3) number of sub-regions (parameters to estimate) and 4) inversion methods to estimate the parameters (scaling factors) for the purpose of assessing the sensitivity introduced by each component and their interactions. 
Geosci. Model Dev. Discuss., doi:10.5194/gmd-2016-213, 2016

Manuscript under review for journal Geosci. Model Dev.

Published: 8 November 2016

(c) Author(s) 2016. CC-BY 3.0 License.

We conducted a series of inversion experiments presented in Table 3 using different combinations of the four components mentioned previously. The experiments progress with increasing deviations from the target fluxes and target transport. E1-E21 and E22-E42 correspond to the two estimation methods of MCMC and CFM, respectively. The results of the experiments

311 should reveal whether the provincial annual and three-monthly total fossil fuel $\mathrm{CO}_{2}$ fluxes and

312 the spatial distributions could be retrieved by the inversion approaches with an acceptable degree of statistical confidence.

Table 3a shows the first (I) set of experiments E1-E7 and E22-E28 used the CT2010 fossil fuel $\mathrm{CO}_{2}$ fluxes to simulate the prior mole fractions for each station. The target modelled mole fractions were simulated using CT2011 fossil fuel $\mathrm{CO}_{2}$ fluxes. The same FLEXPART transport was used to simulate the prior and target mole fractions. In this set of experiments, small flux error was introduced (only within the provincial inversion domains, Table 2), but modelled transport remained perfect. This spatial difference between the prior and target is sometimes referred as the "aggregation error".

Table 3b shows the second set (II), E8-E14 and E29-E35 that were used to assess the impact of transport model error alone on the estimated fluxes. This is achieved by simulating the prior mole fractions in FLEXPART and sampling the target mole fractions (synthetic observations) modelled by CT2011 (using the transport model TM5) with the baseline mole fractions subtracted (see Section 2.4). Both FLEXPART and CarbonTracker used the same set of CT2011 monthly fossil fuel $\mathrm{CO}_{2}$ fluxes. 
Geosci. Model Dev. Discuss., doi:10.5194/gmd-2016-213, 2016

Manuscript under review for journal Geosci. Model Dev.

Published: 8 November 2016

(c) Author(s) 2016. CC-BY 3.0 License.

Table 3c shows the third (III) set, E15-E21 and E36-E42 that were used to assess the combined impacts of transport model and flux errors on the estimated fluxes. This is achieved by simulating the prior mole fractions in FLEXPART using the CT2010 monthly fossil fuel $\mathrm{CO}_{2}$ fluxes and sampling the target mole fractions (synthetic observations) from CT2011 which uses the CT2011 monthly fossil fuel $\mathrm{CO}_{2}$ fluxes. This set of experiments represents more realistic scenarios in which transport and flux errors exist and the experiments can be considered similar to inversions using real observations (e.g. wintertime $\mathrm{CH}_{4}$ ), but possibly with smaller errors. Note that the transport model error includes errors in the simulated synoptic variability by the FLEXPART model and in the baseline mole fractions sampled from the CT2011 using the $5^{\text {th }}$ day end-points of the FLEXPART particle locations.

\section{Model results}

FLEXPART model results were compared with the simulated fossil fuel $\mathrm{CO}_{2}$ mole fractions by CarbonTracker from January through December in 2009 as shown in Fig. 4, an example of one inversion experiment. This example was chosen as an example because it showed the worst case scenario in which prior flux and transport model errors existed. Fig. $4 \mathrm{a}$ and $\mathrm{b}$ shows the inversion results using all thirty-seven and forty-nine sub-regions (census divisions) for $\mathrm{AB}+\mathrm{SK}$ and $\mathrm{ON}$ respectively. Note that stations that are closer to local emission sources show

348 a larger offset between the synoptic and baseline contributions, e.g. Downsview (DOW) station in Ontario. 
Geosci. Model Dev. Discuss., doi:10.5194/gmd-2016-213, 2016

Manuscript under review for journal Geosci. Model Dev.

Published: 8 November 2016

(c) Author(s) 2016. CC-BY 3.0 License.

shown as symbols above (below) the horizontal line at zero. Experiments all used $30 \%$ for $\left(\sigma_{e}\right)^{2}$

354 and $100 \%$ for $\left(\sigma_{\text {prior }}\right)^{2}$ in the CFM method, with the number of sub-regions for the $\mathrm{AB}+\mathrm{SK}$ increasing from 2, 4, 7, 11, 19, 27, 37 respectively, and $\mathrm{ON}$ from 1, 2, 4, 6, 12, 23, 49 respectively. The $30 \%$ prior model-data mismatch $\left(\sigma_{e}\right)^{2}$ is comparable to other real observationbased regional inversion studies, e.g. Gerbig et al. (2003), Zhao et al. (2009), etc. The typical emission inventory uncertainty can range from a few to greater than a hundred percent which depends on the source types and regions (e.g. ECCC, 2015). It appears reasonable to set $\left(\sigma_{\text {prior }}\right)^{2}$ to $100 \%$ (or greater since all these emission uncertainties are poorly known) as in this

361 study. These prior uncertainty settings of $30 \%$ for $\left(\sigma_{e}\right)^{2}$ and $100 \%$ for $\left(\sigma_{\text {prior }}\right)^{2}$ were used in all the remaining sensitivity experiments.

\subsection{Set (I): prior flux error} (MCMC method) and E22-E28 (CFM method) represents conditions in which there is no transport model error, but only flux error exists in the inversion domain. The prior flux is fossil fuel $\mathrm{CO}_{2}$ from CT2010 and the target flux is fossil fuel $\mathrm{CO}_{2}$ from CT2011, both transported by FLEXPART. There are systematic negative errors (red stars in Fig. 5) of the annual total flux estimates using the MCMC method, but they are small compared to the annual relative percentage differences between CT2010 (prior) and CT2011 (target) of $-25 \%$ and $+12 \%$ for $\mathrm{AB}+\mathrm{SK}$ and $\mathrm{ON}$ respectively as presented in Table 2. For instance, using MCMC, the annual total estimation errors have converged to $-4 \%$ and $-1 \%$ for $\mathrm{AB}+\mathrm{SK}$ and $\mathrm{ON}$ respectively for 11 and 4 sub-regions beyond which no significant improvement can be gained. This represent a 
Geosci. Model Dev. Discuss., doi:10.5194/gmd-2016-213, 2016

Manuscript under review for journal Geosci. Model Dev.

Published: 8 November 2016

(c) Author(s) 2016. CC-BY 3.0 License.

375 posterior flux improvement of $\sim 80 \%$ for $\mathrm{AB}+\mathrm{SK}$ and $\sim 90 \%$ for $\mathrm{ON}$ from the prior flux. An

376 indication of substantial flux improvement can be achieved when there is no transport model

377 error. Note that the estimation error does not change as the number of sub-regions increases using

378 MCMC. The errors are stable beyond 11 and 4 sub-regions for $\mathrm{AB}+\mathrm{SK}$ and $\mathrm{ON}$ respectively.

379 This suggests that there is a limit to the number of sub-regions (or unknowns) that the inverse

380 model can optimise for a given setup and constraining observations available, and increasing the

381 number of sub-regions does not necessarily improve the flux estimates. In fact, three unrealistic

382 negative sub-regions appear for some months for $\mathrm{AB}+\mathrm{SK}$ when there are 27 sub-regions to be

383 estimated as shown at the bottom of Fig 5a. The appearance of unrealistic flux estimates suggests

384 the optimization is overfitting the data given the large degrees of freedoms. Synthetic data

385 inversion like the present study is useful for evaluating the inversion setup to ensure that the

386 (near) optimal number of unknowns that can be realistically solved for when real observations are

387 used.

Unlike the MCMC method, estimation errors tend to become more positive as the number of sub-regions increases in the western and eastern regions using the CFM method. The annual errors change from negative to positive by increasing from 1 sub-region to 49 sub-regions in $\mathrm{ON}$, similarly for $\mathrm{AB}+\mathrm{SK}$. It is interesting to note when the 2, 4, 7 sub-regions for $\mathrm{AB}+\mathrm{SK}$ and 1,2 sub-regions for $\mathrm{ON}$ is used, the results of CFM and MCMC are very similar. This indicates that estimating many parameters in high-dimensional space is problematic for CFM. Increasingly large estimation errors appear when high-dimensional parameter space is involved in the inversion. Bielger et al. (2011) noted that parameter-estimation problem using minimization method in particular becomes extremely challenging even with relative few parameters to estimate. 
Geosci. Model Dev. Discuss., doi:10.5194/gmd-2016-213, 2016

Manuscript under review for journal Geosci. Model Dev.

Published: 8 November 2016

(c) Author(s) 2016. CC-BY 3.0 License.

\subsection{Set (II): transport error}

401

The second (II) set of experiments E8-E14 (MCMC) and E29-E35 (CFM) represents

conditions with no flux error, but there is transport model error including the short term (5 days)

403 transport error and the baseline mole fractions (5 days previous) using the FLEXPART model.

The target in this set of experiments is the CT2011 model results at the 7 stations. Both

FLEXPART and CarbonTracker models used CT2011 fossil fuel $\mathrm{CO}_{2}$ emissions as the prior fluxes.

The annual flux errors are positively biased using either MCMC or CFM method shown as blue circles in Fig. 5a and b for $\mathrm{AB}+\mathrm{SK}$ (western region) and $\mathrm{ON}$ (eastern region) respectively. The province of $\mathrm{ON}$ has relatively large error compared to the western region. In contrast to the flux error case for ON, the annual flux error does not change linearly as the number of subregions increases using either of the two inversion methods. In fact, the error peaks at 4 subregions.

It is important to note the following results. Using the MCMC method with 37 subregions (E14) for $\mathrm{AB}+\mathrm{SK}$ and 23 sub-regions (E13) for $\mathrm{ON}$, the annual flux errors are the

417 smallest in this set of experiments with only $1 \%$ and $6 \%$ for $\mathrm{AB}+\mathrm{SK}$ and $\mathrm{ON}$ respectively. The

418 associated standard deviations of the monthly errors (error bars in Figure 5) are relatively small

419 which means that the solution of the flux estimates is relatively stable on the sub-annual time scale. Small errors may appear to be a desirable result, but the flux estimates of the individual sub-regions are unstable and have large positive and negative errors that offset each other. The 
Geosci. Model Dev. Discuss., doi:10.5194/gmd-2016-213, 2016

Manuscript under review for journal Geosci. Model Dev.

Published: 8 November 2016

(c) Author(s) 2016. CC-BY 3.0 License.

numbers of negative unrealistic sub-regions tend to increase with the number of sub-regions in the inversion as shown in brackets at the bottom of Figure 5.

In the CFM results, the annual flux error using the largest number of sub-regions (E35) are $14 \%$ and $37 \%$ for $\mathrm{AB}+\mathrm{SK}$ and $\mathrm{ON}$ respectively. It is consistent with the MCMC results that the standard deviations of the monthly errors using the most number of sub-regions are relatively small except for $\mathrm{AB}+\mathrm{SK}$ in which there is no significant difference in the annual errors using different number of sub-regions. Again, the numbers of negative unrealistic sub-regions are the largest when the annual flux errors appear to be the smallest due to compensating sub-regional errors. This is possibly due to the optimization schemes overfitting the synthetic observations as the possible parameter space expands with the number of sub-regions as noted above. could become large regardless of which optimisation method is used compared to the previous set of experiments in which only flux error exists. This suggests that the accuracy of the posterior fluxes is more dependent on the modelled transport than on the prior fluxes in the experiments we performed. Therefore, the relative importance of this effect highlights the need of using the best possible transport model(s) for inversions to assess uncertainties. In absolute terms, the annual

440 flux errors are relatively small using the MCMC method in comparison with the CFM method, 441 but both estimation methods present difficulty in providing stable and realistic sub-annual and sub-regional flux results when transport model error is large. 
Geosci. Model Dev. Discuss., doi:10.5194/gmd-2016-213, 2016

Manuscript under review for journal Geosci. Model Dev.

Published: 8 November 2016

(c) Author(s) 2016. CC-BY 3.0 License.

\subsection{Set (III): prior flux and transport combined error}

The third (III) set of experiments E15-E21 (MCMC) and E36-E42 (CFM) represents

conditions in which both flux and transport model errors exist. In this set of experiments which

can be considered to be similar to using real observations as constraint, it is likely the flux and

transport errors are in our experiments are smaller than the real data inversions. Similar to the

second (II) set of experiments, the annual errors do not systematically decrease as the number of sub-regions increases in the $\mathrm{MCMC}$ method in the $\mathrm{AB}+\mathrm{SK}$ and $\mathrm{ON}$ regions. As shown in Fig. $5 \mathrm{~b}$ (green squares), the large variability with the number of sub-regions and the similarity of the non-

linear pattern compared to set (II) indicate that the estimation errors are dominated by the transport model error for the ON region. Our results show that transport model error confounds inversion results and increases estimation errors regardless of which optimisation method is used. The cancelling effects (compensating errors) of the prior flux and transport model errors are evident in Figure 5. Similar to the previous set of experiments, the annual flux estimates using different number of sub-regions are fairly stable for $\mathrm{AB}+\mathrm{SK}$ region but again, the results for the ON region are highly unstable.

The correlation plots in Figure 6 can help explain the inversion results. In the prior results, DOW station has a slope of 0.4 while Egbert has a slope of 1.1. The optimisation would try to increase the fluxes from some regions (possibly by a factor of 2 or more to bring the slope closer to 1) to improve the slope at DOW, while at the same time decrease the fluxes from some regions to improve the slope at EGB. The close proximity of EGB and DOW ( 100km apart) and opposing flux requirement have resulted in the unstable posterior solution, giving large increase 
Geosci. Model Dev. Discuss., doi:10.5194/gmd-2016-213, 2016

Manuscript under review for journal Geosci. Model Dev.

Published: 8 November 2016

(c) Author(s) 2016. CC-BY 3.0 License.

large decrease of fluxes or even negative fluxes in some other regions to satisfy nearby EGB. By comparison, the western region of $\mathrm{AB}+\mathrm{SK}$ has prior slopes of less than one at all four sites, resulting in more stable inversion estimates. that plot prior and posterior model results against the synthetic fossil fuel $\mathrm{CO}_{2}$ observations using MCMC with 37 and 49 sub-regions for $\mathrm{AB}+\mathrm{SK}$ and $\mathrm{ON}$ respectively. The regression analyses of the prior and posterior $\mathrm{CO}_{2}$ mole fraction results are shown in blue and red respectively. The improvement of the fit in terms of $\mathrm{R}^{2}$ and the slope of the regression is the most substantial for the DOW station located in ON, which has the largest synoptic variability among all seven stations. Note that stations LLB in AB and DOW in ON have the lowest prior $\mathrm{R}^{2}$. All the inversion cases resulted in better slope and $\mathrm{R}^{2}$ due to data fitting, but the estimation error as presented earlier could be larger than the percentage difference of the prior and target fluxes (Table 2) which means the flux estimates are not necessarily better than the prior fluxes even with larger $\mathrm{R}^{2}$. Thus, improvements in $\mathrm{R}^{2}$ in the posterior mole fractions are not necessarily a validation of the inversion flux results. It is important to recognize that large $\mathrm{R}^{2}$ is not necessarily a measure of stable and realistic flux estimates.

The stability of the posterior flux estimates is evaluated on the monthly and annual time scales. The monthly posterior fluxes and the probability distributions of the annual posterior fluxes are shown in Fig. 7 for the three provinces separately. The priors and targets are shown in gray and green respectively for reference. This figure summarizes the results using experiments 
Geosci. Model Dev. Discuss., doi:10.5194/gmd-2016-213, 2016

Manuscript under review for journal Geosci. Model Dev.

Published: 8 November 2016

(c) Author(s) 2016. CC-BY 3.0 License.

and ON without any unrealistic negative fluxes on both the annual and monthly time scales.

492 These results are compared to experiment E21 in which all 37 and 49 sub-regions for $\mathrm{AB}+\mathrm{SK}$

493 and ON were used respectively. Monthly flux estimates show large intra-annual variability compared to the target (green) fluxes for all three provinces. As shown in Fig. 7 a, the $5^{\text {th }}$ and $95^{\text {th }}$ percentiles (defined here as posterior uncertainties) from the 10,000 ensemble estimates always overlap using 11 and 37 sub-regions for $\mathrm{AB}+\mathrm{SK}$ on the monthly time scale, and statistical distributions for the annual estimates on the right are almost completely overlap for AB. However, there is a large positive bias for $\mathrm{ON}$ as shown in Fig. $7 \mathrm{c}$ using the 4 sub-regions setup.

An important feature in Fig. 7 is that the monthly posterior uncertainties (colored bands) could be underestimated as the uncertainties do not always cover the target fluxes, particularly for

ON region. The relatively large seasonal variation of the inversion results compared to the target dependent on the inversion model setup, transport variations with time (different months and seasons) and inversion domains (west vs east), etc. This could be a part of the reason for the widely different posterior flux estimates from different inversion studies using different transports and setups when the limitations of the inverse models have not been fully characterized.

We will continue to investigate how the posterior uncertainty can be improved (more realistic) in our next set of synthetic data experiments examining the impact of different LPDM transport models, different background baseline mole-fraction estimation, observation station selections, and so on. 
Geosci. Model Dev. Discuss., doi:10.5194/gmd-2016-213, 2016

Manuscript under review for journal Geosci. Model Dev.

Published: 8 November 2016

(c) Author(s) 2016. CC-BY 3.0 License.

\section{Anthropogenic $\mathrm{CH}_{4}$ priors and non-negative constraint}

In this analysis, we examined the sensitivity of inversion results to the prior fluxes. In this

517 case, the CT2010 fossil fuel $\mathrm{CO}_{2}$ fluxes were not used as in Set I (flux error only). Instead 50\%

of the $\mathrm{AB}$ and SK provincial totals calculated from the target CT2011 fossil fuel $\mathrm{CO}_{2}$ were used

to scale the spatial distributions of the anthropogenic (fossil + agriculture + wastes) optimized

a prior with larger difference from the target in terms of both spatial distribution and magnitude.

522 This means that the posterior flux error needs to be less than $50 \%$ (prior flux error), if

improvement can be obtained. Focusing on the $\mathrm{AB}+\mathrm{SK}$ region which has shown robust results spatial distributions of fluxes at $1^{\circ} \times 1^{\circ}$ over $\mathrm{AB}+\mathrm{SK}$ that include, (8a) target CT2011 fossil fuel

$\mathrm{CO}_{2}$, (8b) CT2010 fossil fuel $\mathrm{CO}_{2}$, (8c) $\mathrm{CT}-\mathrm{CH}_{4}$ anthropogenic $\mathrm{CH}_{4}$, and (8d) $\mathrm{CT}_{-}-\mathrm{CH}_{4}$ 
Geosci. Model Dev. Discuss., doi:10.5194/gmd-2016-213, 2016

Manuscript under review for journal Geosci. Model Dev.

Published: 8 November 2016

(c) Author(s) 2016. CC-BY 3.0 License.

The results are consistent with using the CT2010 fossil fuel $\mathrm{CO}_{2}$ as the prior with $25 \%$

538 error for this region. Posterior errors are all less than 50\% which means that improvement could

539 be obtained using any number of sub-regions and different prior PDFs. However, in the normal

540 PDF setup, negative flux sub-regions appeared when more than 7 sub-regions were used and the

541 number increased as the number of sub-regions increased. Increasing the number of sub-regions

542 could worsen the results as shown in the 11, 19, 27 and 37 sub-regions setups. Therefore, greater

543 than $80 \%[(-50 \%-(-7 \%)) /-50 \%$ x $100 \%]$ of prior flux error reduction can be obtained using only

5444 sub-regions without introducing unrealistic fluxes. This is almost identical to the result using

545 CT2010 fossil fuel $\mathrm{CO}_{2}$ as the prior. Although unrealistic negative flux sub-regions could be

546 suppressed in the truncated normal and lognormal PDF setups, the results were not significantly

547 different from using the normal PDF. Errors tend to be more positive using either the truncated

548 normal or the lognormal PDF than those using the normal PDF setup which means that there

549 could be additional biases as a result of the non-negative constraint.

\section{Observational constraint and data selection}

It has been demonstrated in this paper that the transport model error can have a dominant impact on the regional flux estimates. If transport model error is indeed "random", increasing the observational constraints for example, from 1 month (Figure S1) to 3 months (Figure 5) should effectively reduce any biases as a result of small sample size and the impact of the transport model. This is in fact the case when the observational constraints were increased by three folds (i.e. 1 month to 3 months), the estimation errors for $\mathrm{AB}+\mathrm{SK}$ were substantially reduced by $\sim 60 \%$ and stable results were obtained consistently for the two largely different optimisation methods 
Geosci. Model Dev. Discuss., doi:10.5194/gmd-2016-213, 2016

Manuscript under review for journal Geosci. Model Dev.

Published: 8 November 2016

(c) Author(s) 2016. CC-BY 3.0 License.

regardless which optimisation method was used, increasing the observational constraints did not

561 improve or stabilize the results. Another possible strategy could be that when a low prior $\mathrm{R}^{2}$ was

562 pre-calculated (flux and transport combined errors) in real inversions, it would be useful to assess

563 the impact of an individual station.

564

565

566

567

568

569

570

571

572

573

574

575

576

577

578

579

580

Figure 10a and $\mathrm{b}$ shows the sensitivity of the estimation error to any given station. The analyses were based on the same setup in Set II (transport model error only) using 11 and 4 subregions for $\mathrm{AB}+\mathrm{SK}$ and $\mathrm{ON}$ respectively as an illustration. One at a time, a single station was excluded in the experiments E43-E46 (MCMC) and E47-E50 (CFM) for the AB+SK, and E43E45 (MCMC) and E46-E48 (CFM) for the ON region. The dashed reference lines are the errors from the standard cases using all four stations for $\mathrm{AB}+\mathrm{SK}$ and all three stations for $\mathrm{ON}$. For example, Figure 10a suggests that excluding the LLB station (E46) which has the lowest prior $\mathrm{R}^{2}$ ( 0.8) can reduce the annual errors using either MCMC or CFM method. Excluding any other stations in $\mathrm{AB}+\mathrm{SK}$ can worsen the flux estimate in a sense by reducing the observational constraints (amount of well-simulated data available). Recall that all four stations have quite high prior $\mathrm{R}^{2}$ (Figure 6a). Figure 10b shows that excluding the DOW station which has the lowest prior $\mathrm{R}^{2}(\sim 0.3)$ can significantly reduce the errors from the standard three-station setup of $133 \%$ to only $14 \%$ using MCMC, and similarly from $271 \%$ to only $32 \%$ using CFM. Because the FRD station is located far from the major source areas in ON, the FRD data provide little flux constraining power, excluding this station does not significantly affect the flux estimates. This conclusion is consistent between MCMC and CFM. 
Geosci. Model Dev. Discuss., doi:10.5194/gmd-2016-213, 2016

Manuscript under review for journal Geosci. Model Dev.

Published: 8 November 2016

(c) Author(s) 2016. CC-BY 3.0 License.

\section{Discussions}

We have evaluated our regional inversion system using synthetic observations and target

584

585

586

587

588

589

590

591

592

593

594

595

596

597

598

599

600

601

602

603

In this study, the flux signals from outside the inversion domain were not considered explicitly in the optimisation procedure. The FLEXPART model could transport the flux signal from outside the inversion domain over the 5 day integration period differently in comparison to CarbonTracker (another component of the transport error that would contribute to the error of the posterior results). In the next study, it would be useful to test an inversion setup that does optimise the fluxes in this outer region as well as the sensitivity to the estimation of the baseline ("background") mole-fraction value at the beginning of the LPDM integration period (5 days in this study). 
Geosci. Model Dev. Discuss., doi:10.5194/gmd-2016-213, 2016

Manuscript under review for journal Geosci. Model Dev.

Published: 8 November 2016

(c) Author(s) 2016. CC-BY 3.0 License.

There is a consistent pattern across all three provinces and the two inversion methods.

605 There could be a cancelling effect of the errors when both prior flux and transport model errors

606 exist (E15-E21 and E36-E42) and therefore, this effect is possibly a general phenomenon as both

607 the western and eastern region cases showed. In reality, the flux and transport errors are folded

608 together and are not likely to be separable.

609

610

It has been demonstrated in this study (Fig. 7) that the "uncertainty" (defined as the $5^{\text {th }}$ and $95^{\text {th }}$ percentiles in the MCMC estimations) of the posterior fluxes does not always cover the target and is less than the estimation error which suggests that the uncertainty ranges are not yet reliable for further interpretation. Therefore, statistics measure such as "uncertainty reduction" is not shown and discussed.

615

For the region definitions that lead to realistic regional flux estimates, the numbers of subregions for the western region and the eastern region are 11 and 4 respectively. The corresponding annual flux estimation errors for the two regions using the MCMC (CFM) method are $-4 \%$ and $-1 \%(-2 \%$ and $3 \%)$ respectively, when there is only prior flux error. The estimation errors increase to $10 \%$ and $133 \%(16 \%$ and $271 \%)$ resulting from transport model error alone. When prior and transport model errors co-exist in the inversions, the estimation errors become $1 \%$ and $131 \%$ ( $7 \%$ and $264 \%)$. This result indicates that estimation errors are dominated by the transport model error and can in fact cancel each other and propagate to the flux estimates non624 linearly. 
Geosci. Model Dev. Discuss., doi:10.5194/gmd-2016-213, 2016

Manuscript under review for journal Geosci. Model Dev.

Published: 8 November 2016

(c) Author(s) 2016. CC-BY 3.0 License.

improve the fit of the synthetic observations using a large number of sub-regions as shown by the regression plots (Fig. 6), the flux estimates are not necessarily less biased on the annual and regional scales (Fig. 5 and Fig. S2-S13). In fact, unrealistic results can appear on the monthly timescale and for some sub-regions.

632 errors, and their impacts on the intepretation of the results in this study will be discussed as follows. These two types of errors are not likely to be separately quantified and proved their existences in real observation-based inversions. Nevertheless, these two errors will become a part of the total transport model error and optimisation procedure error if they do exist.

\subsection{Representation error} that in fact would not necessarily produce model results matching the CarbonTracker $1^{\circ} \mathrm{x} 1^{\circ}$ results or point observations. However, the mismatch of model resolutions of FLEXPART and CarbonTracker is reduced by using model results representative of afternoon condition with typically well mixed planetary boundary layer and slowly varying mole fractions to capture some

645 of the vertical and horizontal mixing in the atmosphere, thereby minimizing the resolution

646 mismatch of the two models or model to observation in reality. However, we do see large

647 differences when comparing nighttime modelled results. 
Geosci. Model Dev. Discuss., doi:10.5194/gmd-2016-213, 2016

Manuscript under review for journal Geosci. Model Dev.

Published: 8 November 2016

(c) Author(s) 2016. CC-BY 3.0 License.

651 FLEXPART and CarbonTracker can be quite high $\left(\mathrm{R}^{2} \sim 0.8\right)$ before inversion except for the DOW

652 station $\left(\mathrm{R}^{2} \sim 0.3\right)$. Although fluxes and transports are different, the prior mole fractions and

653 synthetic observations are very close which indicate that "representation error" is not a major

654 concern in this study. On the day to day synoptic time scale, no major differences can be found

655 comparing CarbonTracker at $1^{\circ} \times 1^{\circ}$ to FLEXPART at $0.2^{\circ} \times 0.2^{\circ}$ for stations that are not

656 surrounded by high emission sources (e.g. EGB and ETL stations). In reality, this "representation

657 error" will become part of the total transport model error, but it is likely that any representation

658 error will be much smaller than other transport model errors due to e.g. mixing, boundary layer

659 height, and so on.

660

661

\subsection{Aggregation error}

662

The characteristics of aggregation error are likely functions of each individual inversion

663

664

665

666

667

668

669

670

671

672

673 setup. In this study, the cases of prior flux error (Set $\mathbf{I}$ ) and prior flux and transport model error

(Set III), would have "aggregation error"; whereas in the transport error only (Set II) case, would

not have "aggregation error". Our MCMC results showed that Set II without "aggregation error"

have the largest error in the posterior fluxes. While Set I and Set III with "aggregation error"

have smaller posterior flux errors compared to transport error only case (Set II) and increasing

the number of sub-regions (or unknowns) does not improve the posterior flux estimates

significantly. Therefore, "aggregation error" does not represent a large error in our results, and it

needs to be examined for each inversion setup to estimate its possible impact. The coupling

between "aggregation error" and transport error (Set III) could be highly complex and possibly

even offset each other (note each inversion could be different). 
Geosci. Model Dev. Discuss., doi:10.5194/gmd-2016-213, 2016

Manuscript under review for journal Geosci. Model Dev.

Published: 8 November 2016

(c) Author(s) 2016. CC-BY 3.0 License. that transport model errors cannot generally be reduced by aggregating the posterior sub-regional fluxes. The inversion results of this study indicate that large sensitivity to the inversion model setups and the need to evaluate each inversion setup to characterize the inversion model behavior to achieve stable inversion results. Without transport model error, our flux error only case (Set I) does yield information on how many sub-regions are needed to reach robust and realistic results provincially without imposing non-negativity constraints. Increasing the number of sub-regions did not yield significantly better flux estimates. With transport model error (Sets II, III), increasing the number of sub-regions could produce unrealistic posterior results (undetermined sources) sub-regionally.

684

Although using $\mathrm{CH}_{4}$ distribution as the prior has the largest aggregation error among the the number of sub-regions 'in theory' should help reduce aggregation errors, but our inversion results do not improve with increasing number of sub-regions. This gives a measure of the 'resolution' of the inversion setup ( 7 regions in $\mathrm{AB}+\mathrm{SK})$, beyond which other factors dominate (e.g. transport errors etc.). southern Ontario, they appear to be not fully resolved by the dispersion model. This is another indication that regional inversion cannot go below some spatial limit (maybe $\sim 3^{\circ} \times 3^{\circ}$ or $5^{\circ} \times 5^{\circ}$ or larger depending on transport and the observational network) as expected from the dispersive nature of the atmosphere. 
Geosci. Model Dev. Discuss., doi:10.5194/gmd-2016-213, 2016

Manuscript under review for journal Geosci. Model Dev.

Published: 8 November 2016

(c) Author(s) 2016. CC-BY 3.0 License. regions and assuming them to be independent of each other can lead to undetermined sources (Rivier et al., 2010). Kaminsk and Heimann (2001) depicted in Fig. 1 in their comment paper that the estimation error could increase as the number of sub-regions increased. It is not always straightforward to determine the optimal configuration and the number of regions to be optimised as demonstrated in this study particularly when transport model error is large and unknown in reality. Therefore, the main effort in any inverse modelling studies should focus on the performance of the transport model, the region definition and the constraining power of the stations.

\section{Conclusion}

In the development of a regional inversion modelling approach for Canada, this study evaluated various setups and optimisation schemes for regional GHG flux inverse estimation in two different regions in Canada by synthetic-observation inversions. The different sets of experiments progress from small model error to model error comparable to real observation inversion. This approach yielded inversion posterior errors for the different sources of model errors and how these errors interact, as well as finding the suitable model setup for real observation inversion. optimal number of sub-regions for the given inversion setup (using the MCMC optimisation in 
Geosci. Model Dev. Discuss., doi:10.5194/gmd-2016-213, 2016

Manuscript under review for journal Geosci. Model Dev.

Published: 8 November 2016

(c) Author(s) 2016. CC-BY 3.0 License.

721

722

723

724

725

726

727

728

729

730

introducing unrealistic fluxes in the current inversion setups. Inversion based on the near optimal number of sub-regions is helpful for the CFM method as CFM optimisation procedure error can increase with the number of sub-regions being estimated. The CFM estimation errors became increasingly more positive with increasing number of sub-regions, while the MCMC estimation errors approached steady state with increasing number of sub-regions. This suggests the optimisation procedure error (Set $\mathbf{I}$ ) and the prior flux error interact weakly in the inversion. Overall MCMC inversion with perfect model transport worked well, the posterior flux errors are reduced by $\sim 80 \%$ in the western and $\sim 90 \%$ in the eastern domains.

\section{Correct prior flux with transport error experiments (Set II) showed that the current} inversion scheme (adjusting the fluxes only) has (understandably) very limited ability to reduce the transport errors, estimation errors greater than $200 \%$ are possible. For the $\mathrm{AB}+\mathrm{SK}$ domain, MCMC and CFM results are relatively stable with any number of sub-regions, estimation error is less than $20 \%$. While for the ON domain, MCMC and CFM results are less stable with the number of sub-regions and unrealistic negative fluxes are possible when a large number of subregions are estimated. Estimation errors are highly unstable and can range from 6-133\% (by MCMC) and 37-271\% (by CFM). This suggests the current inversion setup in ON is not suitable for real inversion analysis unless a poorly simulated station (DOW) is removed.

$$
\text { The more realistic experiments with both prior flux error and transport error (Set III) }
$$
showed similar posterior results as transport error only case (Set II), as the transport error is the largest error in our case studies. The estimation errors are smaller than Set II, as the errors from Set I (prior flux error case tends to be negative) and Set II (transport error case tends to be positive) offset each other. However, the range of variability for the estimation errors is still 
Geosci. Model Dev. Discuss., doi:10.5194/gmd-2016-213, 2016

Manuscript under review for journal Geosci. Model Dev.

Published: 8 November 2016

(c) Author(s) 2016. CC-BY 3.0 License.

large, similar to Set II. Negative posterior fluxes are possible for large number of sub-regions in $\mathrm{ON}$ and $\mathrm{AB}+\mathrm{SK}$ consistent with Set II results.

747

Overall, MCMC results based on simpler (than CFM) inversion constraint criteria and ensemble methodology have smaller estimation errors and more robustness in our sensitivity analyses than the CFM method (consistent with Miller et al., 2014), but both methods have difficulty to yield stable and realistic flux results when transport model error is large. Synthetic observation inversions provided useful information and identified problems on the different components of prior, transport, estimation errors and estimation uncertainties. There can be danger in doing inversion without proper evaluation of the inversion model (formulation, sensitivity, robustness, stability, etc.), results could have $>200 \%$ estimation error with unrealistically small posterior uncertainties. In this evaluation paper, the $\mathrm{AB}+\mathrm{SK}$ regional inversion results seem reasonable and stable, and this region appears suitable for real observation inversion for slowing varying fluxes such as wintertime $\mathrm{CH}_{4}$.

\section{Code availability}

The FLEXPART model (v8.2) used in this paper can be obtained at 
Geosci. Model Dev. Discuss., doi:10.5194/gmd-2016-213, 2016

Manuscript under review for journal Geosci. Model Dev.

Published: 8 November 2016

(c) Author(s) 2016. CC-BY 3.0 License. model and NOAA ESRL for making the global $\mathrm{CO}_{2}$ and $\mathrm{CH}_{4}$ surface fluxes and 3-D mole fraction fields from CarbonTracker publicly available.

769 spatial resolution of $0.2^{\circ} \times 0.2^{\circ}$ as the emission source sensitivities $\left\{M_{g, p, s, t}\right\}$ (or footprints), where index $\mathrm{g}$ for a given grid cell in space, sub-region $\mathrm{p}$, station $\mathrm{s}$ and time t. $x_{g, p, t}$ is the gridded emission field over sub-region $\mathrm{p}$ at time t. The linear scaling factors of $x_{g, p, t}$ are estimated to fit the synthetic observations $y_{t, s}$ below:

$$
y_{t, s}=\sum_{p \in R_{T}} \lambda_{p} \sum_{g \in G} M_{g, p, t, s} x_{g, p, t}+\epsilon_{t, s}
$$
specific emission sensitivity (footprint) to be summed up over the sub-region $\mathrm{p}$ for each FLEXPART footprint grid cell $\mathrm{g}$ with $\mathrm{G}$ being the total number of grid cells of a given footprint. $\epsilon_{t, s}$ are the residuals to be minimized. For a given time $t$ and station s, summing contributions from all sub-regions to the total number of $\mathrm{R}_{\mathrm{T}}$ sub-regions gives the total modelled mole fraction. station $\mathrm{s}$ at time $\mathrm{t}$. We obtain: 
Geosci. Model Dev. Discuss., doi:10.5194/gmd-2016-213, 2016

Manuscript under review for journal Geosci. Model Dev.

Published: 8 November 2016

(c) Author(s) 2016. CC-BY 3.0 License.

$$
y_{t, s}=\sum_{p \in R_{T}} \lambda_{p} K_{p, t, s}+\epsilon_{t, s}
$$

786

787 where we set the prior $\lambda_{p} \sim N\left(1, \sigma_{\text {prior }}^{2}\right)$, and the model-observation mismatch is $\epsilon_{t, s} \sim N\left(0, \sigma_{\epsilon}^{2}\right)$.

788 The likelihood function $L\left(\boldsymbol{y} \mid \boldsymbol{\lambda}, \sigma_{\epsilon}^{2}\right)$ that assumes $\epsilon_{t, s}$ being i.i.d. becomes:

789

$$
\begin{aligned}
L\left(\boldsymbol{y} \mid \lambda, \sigma_{\epsilon}^{2}\right) & =\prod_{t=1, s=1}^{N}\left(\frac{1}{2 \pi \sigma_{\epsilon}^{2}}\right)^{1 / 2} \exp \left\{\frac{-1}{2 \sigma_{\epsilon}^{2}}\left(y_{t, s}-\sum_{p \in R} \lambda_{p} K_{t, s, p}\right)^{2}\right\} \\
& =\left(\frac{1}{2 \pi \sigma_{\epsilon}^{2}}\right)^{N / 2} \exp \left\{\frac{-1}{2 \sigma_{\epsilon}^{2}} \sum_{t=1, s=1}^{N}\left(y_{t, s}-\sum_{p \in R} \lambda_{p} K_{t, s, p}\right)^{2}\right\}
\end{aligned}
$$

where $N=\sum_{t, s} 1$ is the total number of synthetic observations. In matrix form, the likelihood of the synthetic observations $\boldsymbol{y}_{N \times 1}$ is:

$$
L\left(\boldsymbol{y} \mid \boldsymbol{\lambda}, \sigma_{\epsilon}^{2}\right)=\left(\frac{1}{2 \pi \sigma_{\epsilon}^{2}}\right)^{N / 2} \exp \left\{\frac{-1}{2 \sigma_{\epsilon}^{2}}(\boldsymbol{y}-\boldsymbol{K} \boldsymbol{\lambda})^{T}(\boldsymbol{y}-\boldsymbol{K} \boldsymbol{\lambda})\right\}
$$

non-informative conjugate prior for the variance parameter, $\sigma_{\epsilon}^{2}$, is assumed to follow the inversegamma distribution's probability density function with shape parameter $\alpha$ and scale parameter $\beta$. The probability density function is: 
Geosci. Model Dev. Discuss., doi:10.5194/gmd-2016-213, 2016

Manuscript under review for journal Geosci. Model Dev.

Published: 8 November 2016

(c) Author(s) 2016. CC-BY 3.0 License.

$$
\pi\left(\sigma_{\epsilon}^{2}\right)=\frac{\beta^{\alpha}}{\Gamma(\alpha)}\left(\sigma_{\epsilon}^{2}\right)^{-\alpha-1} \exp \left(-\frac{\beta}{\sigma_{\epsilon}^{2}}\right)
$$

799

800 And the scaling factors $\lambda_{R_{T} \times 1}$ are assumed to be independent and identically distributed (i.i.d.)

801 following the multivariate normal distribution with mean vector $\lambda_{\text {prior }}$ and covariance matrix

$802 \sigma_{\text {prior }}^{2} \boldsymbol{I}_{R_{T}}$ (diagonal matrix). The probability density function for $\boldsymbol{\lambda}$ is:

803

$$
\pi(\lambda)=\left(\frac{1}{2 \pi \sigma_{\text {prior }}^{2}}\right)^{R_{T} / 2} \exp \left\{\frac{-1}{2 \sigma_{\text {prior }}^{2}}\left(\lambda-\lambda_{\text {prior }}\right)^{T}\left(\lambda-\lambda_{\text {prior }}\right)\right\}
$$

804

805

where $\lambda_{\text {prior }}$ is assumed (initialized) to be 1 .

806 to the Bayes' rule, the joint posterior density is:

809

$$
\pi\left(\boldsymbol{\lambda}, \boldsymbol{\sigma}_{\epsilon}^{2} \mid \boldsymbol{y}\right) \propto \pi\left(\sigma_{\epsilon}^{2}\right) \pi(\boldsymbol{\lambda}) L\left(\boldsymbol{y} \mid \boldsymbol{\lambda}, \sigma_{\epsilon}^{2}\right)
$$

810

$$
\pi\left(\boldsymbol{\lambda}, \boldsymbol{\sigma}_{\epsilon}^{2} \mid \boldsymbol{y}\right)=k \pi\left(\sigma_{\epsilon}^{2}\right) \pi(\boldsymbol{\lambda}) L\left(\boldsymbol{y} \mid \boldsymbol{\lambda}, \sigma_{\epsilon}^{2}\right)
$$

812 where $\mathrm{k}$ is a normalizing constant which is to ensure the cumulative distribution (integral) of the

813 joint posterior density equal to 1 . The logarithm of the joint posterior density becomes:

814

$$
\log \left(\pi\left(\boldsymbol{\lambda}, \boldsymbol{\sigma}_{\boldsymbol{\epsilon}}^{2} \mid \boldsymbol{y}\right)\right)=\log (k)+\log \left(\pi\left(\sigma_{\epsilon}^{2}\right)\right)+\log (\pi(\boldsymbol{\lambda}))+\log \left(L\left(\boldsymbol{y} \mid \boldsymbol{\lambda}, \sigma_{\epsilon}^{2}\right)\right)
$$


Geosci. Model Dev. Discuss., doi:10.5194/gmd-2016-213, 2016

Manuscript under review for journal Geosci. Model Dev.

Published: 8 November 2016

(c) Author(s) 2016. CC-BY 3.0 License.

where $\lambda$ is the vector of scaling factor parameters (regression coefficients). The term $\log \left(\pi\left(\sigma_{\epsilon}^{2}\right)\right)$

817 is the log of the prior probability density for the model-observation mismatch error. The term

$818 \log (\pi(\lambda))$ is the sum of the $\log$ of the prior probability densities for the scaling factors. The term

$819 \log \left(L\left(\boldsymbol{y} \mid \boldsymbol{\lambda}, \sigma_{\epsilon}^{2}\right)\right)$ is the $\log$ likelihood given the parameters (i.e. the multiple linear regression

820 model used to fit the synthetic observations). It is difficult to analytically solve for the parameters

821 in Eq. (A10). In most cases for Bayesian analyses, therefore, $\lambda$ are sampled from the (complex)

822 joint posterior density using MCMC. The random-walk Metropolis algorithm that is applied in

823 this study is one of the MCMC methods, which is briefly described as follows:

824

Suppose I samples (number of iterations) are drawn from a multivariate distribution with probability density function $f(\boldsymbol{\lambda} \mid \boldsymbol{y})$. Suppose $\lambda^{i}$ is the $\mathrm{i}^{\text {th }}$ sample from $f$, where $\lambda^{i}=$ $\left(\lambda_{1}, \lambda_{2}, \cdots, \lambda_{p}\right)^{T}$ is the transposed vector of scaling factors and $\mathrm{p}$ is the number of sub-regions in this study. To use the Metropolis algorithm, an initial value $\lambda^{0}$ and a multivariate proposal density $q\left(\lambda^{i+1} \mid \lambda^{i}\right)$ are required. For the $(i+1)^{\text {th }}$ iteration, the algorithm generates a sample from a $q(. \mid$.$) based on the current sample \lambda^{i}$, and it makes a decision to either accept or reject the new sample. If the new sample is accepted, the algorithm repeats itself by starting at the new sample.

If the new sample is rejected, the algorithm starts at the current point and repeats. Suppose $q\left(\lambda_{\text {new }} \mid \lambda^{i}\right)$ is a symmetric distribution. The proposal distribution should be a simple (e.g.

Gaussian or unimodal) distribution from which to sample, and it must be such that $q\left(\lambda_{\text {new }} \mid \lambda^{i}\right)=$ $q\left(\lambda^{i} \mid \lambda_{\text {new }}\right)$, meaning that the likelihood of jumping to $\lambda_{\text {new }}$ from $\lambda^{i}$ is the same as the likelihood of jumping back to $\lambda^{i}$ from $\lambda_{\text {new }}$. The most common choice of the proposal distribution is the multivariate normal distribution $N(\boldsymbol{\lambda}, \boldsymbol{\Sigma})$, with p-dimensional mean vector $\lambda$ 
Geosci. Model Dev. Discuss., doi:10.5194/gmd-2016-213, 2016

Manuscript under review for journal Geosci. Model Dev.

Published: 8 November 2016

(c) Author(s) 2016. CC-BY 3.0 License.

and $\mathrm{p} \times \mathrm{p}$ covariance matrix $\boldsymbol{\Sigma}$. The random-walk Metropolis algorithm can be summarized as

839 follows:

840

- Set $\mathrm{n}=0$. Choose a starting point $\lambda^{\mathbf{0}}$. This can be an arbitrary point as long as $\boldsymbol{f}\left(\boldsymbol{\lambda}^{\mathbf{0}} \mid \boldsymbol{y}\right)>$ 0.

- Generate a new sample, $\lambda_{\text {new }}$, by using the proposal distribution $\boldsymbol{q}\left(\cdot \mid \lambda^{i}\right)$.

- Calculate the following quantity: $\quad r=\min \left\{\frac{f\left(\lambda_{\text {new }} \mid y\right)}{f\left(\lambda^{i} \mid y\right)}, \mathbf{1}\right\}$

- Draw a random sample u from the uniform distribution $\boldsymbol{U}(\mathbf{0}, \mathbf{1})$,

- $\quad$ Set $\lambda^{i+1}=\lambda_{\text {new }}$ if $\mathrm{u}<\mathrm{r}$; otherwise set $\lambda^{i+1}=\lambda^{i}$.

- Set $\boldsymbol{i}=\boldsymbol{i}+\mathbf{1}$. If $\boldsymbol{i}<\boldsymbol{I}$, the number of desired samples, return to step 2. Otherwise, stop. desired distribution $f(\boldsymbol{\lambda} \mid \boldsymbol{y})$, and so from some point forward, the chain of samples is a sample from the distribution of interest. In Markov chain terminology, this distribution is called the stationary distribution of the chain, and in Bayesian statistics, it is the posterior distribution of the model parameters (scaling factors in this study).

For detailed descriptions and proofs in MCMC method and Bayesian analysis, there are articles and books including Besag et al. (1995), Chib and Greenberg (1995), Gilks et al. (1996) and Kass et al. (1998). Here we only describe the steps and diagnostics that were used to conduct MCMC simulations for the purpose of parameter estimations in this synthetic flux inversion 
Geosci. Model Dev. Discuss., doi:10.5194/gmd-2016-213, 2016

Manuscript under review for journal Geosci. Model Dev.

Published: 8 November 2016

(c) Author(s) 2016. CC-BY 3.0 License. uncertainty for the emissions in each sub-region. The variance parameter $\left(\sigma_{e}\right)^{2}$ can be considered as the total model-observation mismatch (or total model error). This parameter is assumed to

863 have the inverse-gamma distribution. The mean of $\left(\sigma_{e}\right)^{2}$ is calculated as scale/(shape -1$)$ when

864 shape is greater than 1 and variance of $\left(\sigma_{e}\right)^{2}$ is equal to scale ${ }^{2} /\left[(\text { shape- } 1)^{2}\right.$ (shape-2)] when shape

865 is greater than 2. With the shape and scale parameters being set to 2.001 and 1.001 , this gives a

866 mean of 1 and variance of 1000 which is similar to setting a large uncertainty for the model-

867 observation mismatch error. This large prescribed uncertainty corresponds to conjugate non-

868 informative prior for the $\left(\sigma_{e}\right)^{2}$. Conjugate priors are required to ensure the target posterior

869 distribution having a closed form. This total model-observation mistmatch error has been

870 estimated to be about $30 \%$ in previous studies that used the CFM method (Zhao et al., 2009;

871 Gerbig et al., 2003; among others) which included measurement error, transport error,

872 aggregation error and so on.

873

874

In previous inverse modelling studies the parameters of interest were assumed to be fixed constants and determined by the analytical cost function minimization. Instead of treating parameters as fixed constant, we applied Bayesian analysis with MCMC random sampling method that treated parameters as random variables. Often times, these parameters cannot be determined exactly, and particularly the uncertainty about the parameter has no known analytical form in a high-dimensional parameter distribution space. Using MCMC sampling method, our inference was based on the probability distribution for the parameter. In this paper, we did not address the impact of the covariances in the uncertainty matrices, or the magnitude of the 
Geosci. Model Dev. Discuss., doi:10.5194/gmd-2016-213, 2016

Manuscript under review for journal Geosci. Model Dev.

Published: 8 November 2016

(c) Author(s) 2016. CC-BY 3.0 License.

882

883

884

885

886

887

888

889

890

891

892

893

894

895

896

897

898

899

900

901

902

903

904

905

assumed prior emission and model uncertainties. Hence, the off-diagonal elements in the covariance matrix were simply set to zeros.

There is no simple way to calculate the uncertainties of the posterior distributions of the scaling factors. In fact an analytical form of the uncertainties is not required in our simulation approach. Within the Bayesian framework, conducting simulation to estimate the uncertainties for parameter of interests becomes straightforward because the posterior distributions of scaling factors (uncertainties about the posterior scaling factors) can be obtained by simulation while taking into account the uncertainties in all the parameters by treating them as random variables $\left(\right.$ SAS/STAT $\left.^{\circledR}, 2013\right)$. We performed Bayesian analysis for January through December 2009 for every three months. The MCMC procedure which uses the random-walk Metropolis algorithm to sample the posterior probability density expressed in Eq. (A10) in which the SAS/STAT ${ }^{\circledR}$ system was used to conduct the simulations.

In total 110,000 samples (scaling factor estimates) were drawn by MCMC simulations for every three months in year 2009. 10,000 burn-in samples were used to minimize the effect of the initial values (all scaling factors were initialized to 1) on the posterior inference, that is, the initial 10,000 drawn MCMC samples were discarded. A thinning rate of 10 was used to reduce sample autocorrelations. Although 110,000 iterations were conducted, only every $10^{\text {th }}$ sample was kept for subsequent inferences for the posterior flux estimates to minimize autocorrelation. All diagnostic trace plots (not shown) for all the parameters (scaling factors) showed good mixing (fast convergence), that was, the efficiency that the posterior parameter space was explored by the Markov chain. This was a good indication of the sub-regions that were not strongly correlated in space due to similar transport. Hence, there was no serious multi-linearity problem of the 
Geosci. Model Dev. Discuss., doi:10.5194/gmd-2016-213, 2016

Manuscript under review for journal Geosci. Model Dev.

Published: 8 November 2016

(c) Author(s) 2016. CC-BY 3.0 License.

parameters in the regression model (likelihood function). It also means that the Markov chain

907 quickly traversed the support of the distribution to explore both the tails and the mode areas

908 efficiently and the parameters reached their stationary distributions. Geweke diagnostics showed

909 constant mean and variance of the Markov Chain. Heidelberger and Welch diagnostics showed

910 stationarity of the Markov chain. Raftery and Lewis diagnostics showed the number of iterations

911 was sufficient to estimate the percentiles of the parameters. The effective sample size calculated

912 also showed that the number of iterations used was sufficient for inferences. The Monte Carlo

913 standard errors of the mean estimates for each of the parameters were small, with respect to the

914 posterior standard deviations. This means that only a fraction (less than 1\%) of the posterior

915 variability was due to the simulation.

916

917 In all but the simplest cases of inversions that have low dimensions (i.e. only a few

918 parameters), it is not possible to estimate parameters from a complicated joint posterior

919 distribution directly and analytically. Often, Bayesian methods rely on simulations to generate

920 samples from the desired posterior distribution and use the simulated draws to approximate the

921 distribution and to make statistical inferences, and this was carried out in this study for

922 comparison. Note that however, the definition of central estimators such as the mean or the

923 median and of estimators of uncertainty such as the error variance-covariance matrix fail to have

924 any useful representativeness in a high-dimensional problem in which the posterior distributions

925 of the parameters can actually be multi-modal. Therefore, the common practice of reporting the

926 means or medians posterior estimates should be abandoned, even if the results are accompanied

927 by some analysis of error (Tarantola, 2005).

928 
Geosci. Model Dev. Discuss., doi:10.5194/gmd-2016-213, 2016

Manuscript under review for journal Geosci. Model Dev.

Published: 8 November 2016

(c) Author(s) 2016. CC-BY 3.0 License.

Andres, R. J., Gregg, J. S., Losey, L., Marland, G., and Boden, T. A.: Monthly, global emissions of carbon dioxide from fossil fuel consumption, Tellus B, 63, 309-327, doi:10.1111/j.16000889.2011.00530.x, 2011.

Bergamaschi, P., Krol, M., Dentener, F., Vermeulen, A., Meinhardt, F., Graul, R., Ramonet, M., Peters, W., and Dlugokencky, E. J.: Inverse modelling of national and European $\mathrm{CH}_{4}$ emissions using the atmospheric zoom model TM5, Atmos. Chem. Phys., 5, 2431-2460, doi:10.5194/acp-52431-2005, 2005.

Bergamaschi, P., Krol, M., Meirink, J. F., Dentener, F., Segers, A., van Aardenne, J., Monni, S., Vermeulen, A., Schmidt, M., Ramonet, M., Yver, C., Meinhardt, F., Nisbet, E. G.,

Fisher, R., O'Doherty, S., and Dlugokencky, E. J.: Inverse modeling of European $\mathrm{CH}_{4}$ emissions 2001-2006, J. Geophys. Res., 115, D22309, doi:10.1029/2010JD014180, 2010.

Besag, J., Green, P., Higdon, D., and Mengersen, K.: Bayesian computation and stochastic systems, Stat. Sci. 10, 3-66, 1995.

Biegler, L., Biros, G., Ghattas, O., Heinkenschloss, M., Keyes, D., Mallick, B., Marzouk, Y., Teno- rio, L., Waanders, B. V. B., and Willcox, K.: Large-Scale Inverse Problems and Quantification of Uncertainty, Computational Statistics, John Wiley \& Sons Ltd, UK, 2011.

Bocquet, M.: Grid resolution dependence in the reconstruction of an atmospheric tracer source. Nonlinear Process Geophys 12:219-234, 2005.

Boden, T. A., Marland, G. and Andres, R. J.: Global, Regional, and National Fossil-Fuel $\mathrm{CO}_{2}$ Emissions. Carbon Dioxide Information Analysis Center, Oak Ridge National Laboratory, U.S. Department of Energy, Oak Ridge, Tenn., USA, doi:10.3334/CDIAC/00001_V2013, 2013.

Brioude, J., Kim, S.-W., Angevine, W. M., Frost, G. J., Lee, S.-H., McKeen, S. A., Trainer, M., Fehsenfeld, F. C., Holloway, J. S., Ryerson, T. B., Williams, E. J., Petron, G., and Fast, J. D.: Top-down estimate of anthropogenic emission inventories and their interannual variability in Houston using a mesoscale inverse modeling technique, J. Geophys. Res., 116, D20305, doi:10.1029/2011JD016215, 2011.

Brioude, J., Petron, G., Frost, G. J., Ahmadov, R., Angevine, W. M., Hsie, E.-Y., Kim, S.-W., Lee, S.-H., McKeen, S. A., Trainer, M., Fehsenfeld, F. C., Holloway, J. S., Peischl, J., Ryerson, T. B., and Gurney, K. R.: A new inversion method to calculate emission inventories without a prior at mesoscale: application to the anthropogenic $\mathrm{CO}_{2}$ emission from Houston, Texas, 30 J. Geophys. Res., 117, D05312, doi:10.1029/2011JD016918, 2012.

Brioude, J., Angevine, W. M., Ahmadov, R., Kim, S.-W., Evan, S., McKeen, S. A., Hsie, E.-Y., Frost, G. J., Neuman, J. A., Pollack, I. B., Peischl, J., Ryerson, T. B., Holloway, J., Brown, S. S., Nowak, J. B., Roberts, J. M., Wofsy, S. C., Santoni, G. W., Oda, T., and Trainer, M.:

973 Top-down estimate of surface flux in the Los Angeles Basin using a mesoscale inverse modeling 
Geosci. Model Dev. Discuss., doi:10.5194/gmd-2016-213, 2016

Manuscript under review for journal Geosci. Model Dev.

Published: 8 November 2016

(c) Author(s) 2016. CC-BY 3.0 License.

974

975

976

977

978

979

980

981

982

983

984

985

986

987

988

989

990

991

992

993

994

995

996

997

998

999

1000

1001

1002

1003

1004

1005

1006

1007

1008

1009

1010

1011

1012

1013

1014

1015

1016

1017

1018

1019

1020

technique: assessing anthropogenic emissions of $\mathrm{CO}, \mathrm{NOx}$ and $\mathrm{CO}_{2}$ and their impacts, Atmos. Chem. Phys., 13, 3661-3677, doi:10.5194/acp-13-3661-2013, 2013.

Bruhwiler, L., Dlugokencky, E., Masarie, 5 K., Ishizawa, M., Andrews, A., Miller, J., Sweeney, C., Tans, P., and Worthy, D.: CarbonTracker- $\mathrm{CH}_{4}$ (2014), an assimilation system for estimating emissions of atmospheric methane, Atmos. Chem. Phys., 14, 8269-8293, doi:10.5194/acp14-8269-2014, 2014.

CarbonTracker: CT2011 results provided by NOAA ESRL, Boulder, Colorado, USA, available at: http://carbontracker.noaa.gov (last access: 25 November 2013), 2010, 2011.

Chib, S. and Greenberg, E.: Understanding the Metropolis-Hastings algorithm, Am. Stat., 49, 327-335, 1995. Congdon, P.: Bayesian Statistical Modeling, 2nd edn., John Wiley \& Sons, New York, USA, 2006.

Cooper, O. R., Parrish, D. D., Stohl, A., Trainer, M., Nedelec, P., and Thouret, V.: Increasing springtime ozone mixing ratios in the free troposphere over western North America, Nature, 463, 344-348, 2010.

Cressot, C., Chevallier, F., Bousquet, P., Crevoisier, C., Dlugokencky, E. J., Fortems-Cheiney, A., Frankenberg, C., Parker, R., Pison, I., Scheepmaker, R. A., Montzka, S. A., Krummel, P. B., Steele, L. P., and Langenfelds, R. L.: On the consistency between global and regional methane emissions inferred from SCIAMACHY, TANSO-FTS, IASI and surface measurements, Atmos. Chem. Phys., 14, 577-592, doi:10.5194/acp-14-577-2014, 2014.

Enting, I. G., Francey, R. J., Trudinger, C. M., and Granek, H.: Synthesis Inversion of Atmospheric $\mathrm{CO}_{2}$ Using the GISS Tracer Transport Model, Tech. Rep. Technical Paper no. 29, CSIRO Division of Atmospheric Research, Commonwealth Scientific and Industrial Research Organization, Atmos. Res., Australia, 1993.

Enting, I. G., Trudinger, C. M., and Francey, R. J.: A synthesis inversion of the concentration and $13 \mathrm{C}$ of atmospheric $\mathrm{CO}_{2}$, Tellus, 47B, 35-52, 1995.

Environment and Climate Change Canada (ECCC), National Inventory Report 1990-2013: Greenhouse Gas Sources and Sinks in Canada, available at: http://www.ec.gc.ca/gesghg/default.asp?lang=En\&n=83A34A7A-1 (last access: 22 October 2015), 2015.

Fan, S., Gloor, M., Mahlman, J., Pacala, S., Sarmiento, J., Takahashi, T., and Tans, P.: A large terrestrial carbon sink in North America implied by atmospheric and oceanic $\mathrm{CO}_{2}$ data and models, Science, 282, 442-446, 1998.

Fan, S.-W., Gloor, M., Mahlman, J., Pacala, S. W., Sarmiento, J. L., Takahashi, T., and Tans, P.: On the use of regularization techniques in the inverse modeling of atmospheric carbon dioxide, J. Geophys. Res., 104, 21503-21512, doi:10.1029/1999JD900215, 1999.

Gerbig, C., Lin, J. C., Wofsy, S. C., Daube, B. C., Andrews, A. E., Stephens, B. B., Bakwin, P. S., and Grainger, C. A.: Toward constraining regional-scale fluxes of $\mathrm{CO}_{2}$ with atmospheric 
Geosci. Model Dev. Discuss., doi:10.5194/gmd-2016-213, 2016

Manuscript under review for journal Geosci. Model Dev.

Published: 8 November 2016

(c) Author(s) 2016. CC-BY 3.0 License.

observations over a continent: 1. Observed spatial variability from airborne platforms, J. Geophys. Res., 108, 4756, doi:10.1029/2002JD003018, 2003.

Gilks, W. R., Richardson, S., and Spiegelhalter, D. J.: Markov Chain Monte Carlo in Practice, Chapman \& Hall, London, UK, 1996.

Gourdji, S. M., Hirsch, A. I., Mueller, K. L., Yadav, V., Andrews, A. E., and Michalak, A. M.: Regional-scale geostatistical inverse modeling of North American $\mathrm{CO}_{2}$ fluxes: a synthetic data study, Atmos. Chem. Phys., 10, 6151-6167, doi:10.5194/acp-10-6151-2010, 2010.

Gurney, K. R., Law, R. M., Denning, A. S., Rayner, P. J., Baker, D., Bousquet, P., Bruhwiler, L., Chen, Y. H., Ciais, P., Fan, S., Fung, I. Y., Gloor, M., Heimann, M., Higuchi, K., John, J., Maki, T., Maksyutov, S., Masarie, K., Peylin, P., Prather, M., Pak, B. C., Randerson, J., Sarmiento, J., Taguchi, S., Takahashi, T. and Yuen, C. W.: Towards robust regional estimates of $\mathrm{CO}_{2}$ sources and sinks using atmospheric transport models, Nature, 415(6872), 626-630, doi:10.1038/415626a.

Jeong, S., Zhao, C., Andrews, A. E., Bianco, L., Wilczak, J. M., and Fischer, M. L.: Seasonal variation of $\mathrm{CH}_{4}$ emissions from central California, J. Geophys. Res., 117, D11306, doi:10.1029/2011JD016896, 2012.

Kaminski, T., and M. Heimann: Inverse modeling of atmospheric carbon dioxide fluxes, Science, 294, 259-260, 2001.

Kass, R. E., Carlin, B. P., Gelman, A., and Neal, R. M.: Markov Chain Monte Carlo in practice: a roundtable discussion, Stat. Sci., 52, 93-100, 1998.

Kort, E. A., Eluszkiewicz, J., Stephens, B. B., Miller, J. B., Gerbig, C., Nehrkorn, T., Daube, B. C., Kaplan, J. O., Houweling, S., and Wofsy, S. C.: Emissions of $\mathrm{CH}_{4}$ and $\mathrm{N}_{2} \mathrm{O}$ over the United States and Canada based on a receptor-oriented modeling framework and COBRA-NA atmospheric observations, Geophys. Res. Lett., 35, L18808, doi:10.1029/2008GL034031, 2008.

Lin, J.C., Gerbig, C., Wofsy, S.C., Andrews, A.E., Daube, B.C., Grainger, C.A., Stephens, B.B. Bakwin, P.S. and Hollinger, D.Y.: Measuring fluxes of trace gases at regional scales by Lagrangian observations: Application to the $\mathrm{CO}_{2}$ Budget and Rectification Airborne (COBRA) study. Journal of Geophysical Research-Atmospheres, (2004) 109(D15): D15304, DOI: 10.1029/2004JD004754.

Liu, J. S.: Monte Carlo Strategies in Scientific Computing, Springer, New York, USA, 2001.

Manning, A. J., Ryall, D. B., Derwent, R. G., Simmonds, P. G., and O’Doherty, S.: Estimating UK methane and nitrous oxide emissions from 1990 to 2007 using an inversion modelling approach, J. Geophys. Res. 116, D02305, doi:10.1029/2010JD014763, 2011.

Miller, S. M., Wofsy, S. C., Michalak, A. M., Kort, E. A., Andrews, A. E., Biraud, S. C., Dlugokencky, E. J., Eluszkiewicz, J., Fischer, M. L., Janssens-Maenhout, G., Miller, B. R., 
Geosci. Model Dev. Discuss., doi:10.5194/gmd-2016-213, 2016

Manuscript under review for journal Geosci. Model Dev.

Published: 8 November 2016

(c) Author(s) 2016. CC-BY 3.0 License.

Miller, J. B., Montzka, S. A., Nehrkorn, T., and Sweeney, C.: Anthropogenic emissions of methane in the United States, P. Natl. Acad. Sci., 110, 20018-20022, doi:10.1073/pnas.1314392110, 2013.

Miller, S. M., Michalak, A. M., and Levi, P. J.: Atmospheric inverse modeling with known physical bounds: an example from trace gas emissions, Geosci. Model Dev., 7, 303-315, doi:10.5194/gmd-7-303-2014, 2014.

Oda, T. and Maksyutov, S.: A very high-resolution ( $1 \mathrm{~km} \mathrm{x} 1 \mathrm{~km})$ global fossil fuel $\mathrm{CO}_{2}$ emission inventory derived using a point source database and satellite observations of nighttime lights, Atmos. Chem. Phys., 11, 543-556, doi:10.5194/acp-11-543-2011, 2011.

Peters et al., 2007, "An atmospheric perspective on North American carbon dioxide exchange: CarbonTracker", PNAS, November 27, 2007, vol. 104, no. 48, 18925-18930, with updates documented at http://carbontracker.noaa.gov.

Peylin, P., Bousquet, P. and Ciais, P.: Inverse modeling of atmospheric carbon dioxide fluxes response. Science 294(5550):2292-2292, 2001.

Rigby, M., Manning, A. J., and Prinn, R. G.: Inversion of long-lived trace gas emissions using combined Eulerian and Lagrangian chemical transport models, Atmos. Chem. Phys., 11, 9887-9898, doi:10.5194/acp-11-9887-2011, 2011.

Rivier, L., Peylin, P., Ciais, P., Gloor, M., Rödenbeck, C., Geels, C., Karstens, U., Bousquet, P., Rayner, P., Brandt, J., and Heimann, M.: European $\mathrm{CO}_{2}$ fluxes from atmospheric inversions using regional and global transport models, Clim. Change, 103, 93-115, doi:10.1007/s10584010-9908-4, 2010.

Roberts, G. O.: Markov chain concepts related to sampling algorithms, in: Markov Chain Monte Carlo in Practice, edited by: Gilks, W. R. Spiegelhalter, D. J. and Richardson, S., Chapman \& Hall, London, UK, 45-58, 1996.

Rodgers, C. D.: Inverse Methods for Atmospheric Sounding: Theory and Practice, World Scientific Publishing Co. Ltd, Singapore, 2000.

SAS Institute Inc.: SAS/STAT® 13.2 User's Guide, 2nd edn., SAS Institute Inc., Cary, NC, USA, 2013.

Stohl, A., Forster, C., Eckhardt, S., Spichtinger, N., Huntrieser, H., Heland, J., Schlager, H., Aufmhoff, H., Arnold, F., and Cooper, O. R.: A backward modeling study of intercontinental pollution transport using aircraft measurements, J. Geophys. Res., 108, 4370, doi:10.1029/2002JD002862, 2003.

Stohl, A., Forster, C., Frank, A., Seibert, P., and Wotawa, G.: Technical note: The Lagrangian particle dispersion model FLEXPART version 6.2, Atmos. Chem. Phys., 5, 2461-2474, doi:10.5194/acp-5-2461-2005, 2005. 
Geosci. Model Dev. Discuss., doi:10.5194/gmd-2016-213, 2016

Manuscript under review for journal Geosci. Model Dev.

Published: 8 November 2016

(c) Author(s) 2016. CC-BY 3.0 License.

1115 Stohl, A., Seibert, P., Arduini, J., Eckhardt, S., Fraser, P., Greally, B. R., Lunder, C., Maione, M., 1116 Mühle, J., O’Doherty, S., Prinn, R. G., Reimann, S., Saito, T., Schmidbauer, N., Simmonds, 1117 P. G., Vollmer, M. K.,Weiss, R. F., and Yokouchi, Y.: An analytical inversion method for 1118 determining regional and global emissions of greenhouse gases: sensitivity studies and 1119 application to halocarbons, Atmos. Chem. Phys., 9, 1597-1620, doi:10.5194/acp-9-1597-2009, 11202009.

1121

1122

1123

1124

1125

1126

1127

1128

1129

1130

1131

1132

1133

1134

1135

1136

1137

1138

Tarantola, A.: Inverse problem theory and methods for model parameter estimation, SIAM, Philadelphia, PA, USA, 2005.

Thompson, R. L., Gerbig, C., and Rödenbeck, C.: A Bayesian inversion estimate of N2O emissions for western and central Europe and the assessment of aggregation errors, Atmos. Chem. Phys., 11, 3443-3458, doi:10.5194/acp-11-3443-2011, 2011.

Tolk, L. F., Dolman, A. J., Meesters, A. G. C. A., and Peters, W.: A comparison of different inverse carbon flux estimation approaches for application on a regional domain, Atmos. Chem. Phys., 11, 10349-10365, doi:10.5194/acp-11-10349-2011, 2011.

Vogel, F. R., Ishizawa, M., Chan, E., Chan, D., Hammer, S., Levin, I. and Worthy, D. E. J.: Regional non- $\mathrm{CO}_{2}$ greenhouse gas fluxes inferred from atmospheric measurements in Ontario,Canada. J. Integr. Environ. Sci. 9, 41-55. doi:10.1080/1943815X.2012.691884, 2012.

Zhao, C., Andrews, A. E., Bianco, L., Eluszkiewicz, J., Hirsch, A., MacDonald, C., Nehrkorn, T., and Fischer, M. L.: Atmospheric inverse estimates of methane emissions from Central California, 1139 J. Geophys. Res., 114, D16302, doi:10.1029/2008JD011671, 2009. 
Geosci. Model Dev. Discuss., doi:10.5194/gmd-2016-213, 2016

Manuscript under review for journal Geosci. Model Dev.

Published: 8 November 2016

(c) Author(s) 2016. CC-BY 3.0 License.

1141

1142

1143

1144

1145

1146

1147

1148

1149

1150

1151

1152

1153

1154

1155

1156

1157

1158

1159

1160

1161

1162

1163

1164

1165

1166

1167

1168

1169

1170

1171

1172

1173

1174

1175

1176

1177

1178

1179

1180

1181

1182

1183

1184

Figure 1. Schematic of the inversion experiments that have prior flux and transport errors.

Figure 2. (a) the spatial definitions for inversion using 2 sub-regions on the left panel for Alberta and Saskatchewan $(\mathrm{AB}+\mathrm{SK})$ and 1 sub-region on the right panel for $\mathrm{ON}$ provinces. (b) 4 and 2 sub-regions for $\mathrm{AB}+\mathrm{SK}$, ON provinces respectively. (c) 7 and 4 sub-regions for $\mathrm{AB}+\mathrm{SK}, \mathrm{ON}$ provinces respectively. (d) 11 and 6 sub-regions for $\mathrm{AB}+\mathrm{SK}$, ON provinces respectively. (e) 19 and 12 sub-regions for $\mathrm{AB}+\mathrm{SK}$, $\mathrm{ON}$ provinces respectively. (f) 27 and 24 sub-regions for $\mathrm{AB}+\mathrm{SK}, \mathrm{ON}$ provinces respectively. (g) 37 and 49 sub-regions (census divisions) for $\mathrm{AB}+\mathrm{SK}$ and $\mathrm{ON}$ provinces respectively. Sub-regional totals are color coded in $\mathrm{Mt} / \mathrm{month}$. Four stations were used in inversion experiments for $\mathrm{AB}+\mathrm{SK}$ and three stations for $\mathrm{ON}$ shown as star symbols. Note that the northern part of the map for ON province is clipped. Examples of the fossil fuel spatial distributions of $\mathrm{CO}_{2}$ fluxes are shown for January 2009 for $\mathrm{AB}+\mathrm{SK}$ and $\mathrm{ON}$ obtained from the releases of CT2010 and CT2011. The January monthly provincial totals in mega-tonnes (Mt) are shown in the top right corners.

Figure 3. Mean footprint emission sensitivity in picoseconds per kilogram obtained from FLEXPART 5-day backward simulations (21 UTC daily) averaged over all footprints of 7 stations and for January through December 2009. Measurement stations are marked with white stars. The western $(\mathrm{AB}+\mathrm{SK})$ and eastern $(\mathrm{ON})$ inversion domains are in thick black boundaries.

Figure 4. (a) and (b) model results of experiment E21 using the MCMC method for stations in $\mathrm{AB}+\mathrm{SK}$ (37 sub-regions) and $\mathrm{ON}$ (49 sub-regions) respectively. The prior and posterior mole fractions are shown in blue and red respectively. The target mole fractions (synthetic observations) simulated by CT2011 are shown in black.

Figure 5. Annual estimation errors (relative percentage difference of the posterior estimates from the target flux) for set (I): flux error, set (II): transport error, and set (III): flux and transport error cases for (a) provinces of AB and SK combined and (b) province of ON. Experiments E1-E21 and E22-E42 correspond to the results obtained from the MCMC and CFM methods respectively. Fluxes were estimated every three months using three months of model results. See Section 3 for explanations of the results.

Figure 6. (a) and (b) linear regression analyses of experiment E21 using the MCMC method for stations in $\mathrm{AB}+\mathrm{SK}$ (37 sub-regions) and $\mathrm{ON}$ (49 sub-regions) respectively, using January to December 2009 posterior (red) and prior (blue) results.

Figure 7. Monthly (left) and annual (right) fossil fuel $\mathrm{CO}_{2}$ posterior flux estimates (in Mt) for experiments E17, E18 (blue) and E21 (red) in comparison with the monthly prior (gray) and target (green) fluxes for the provinces of $\mathrm{AB}, \mathrm{SK}$ and $\mathrm{ON}$ using MCMC. The monthly mean posterior estimates are shown as connecting lines. The colored bands associated with the respective experiments show the $5^{\text {th }}$ and $95^{\text {th }}$ percentiles of the monthly flux estimates calculated from the 10,000 MCMC simulated scaling factors for the individual months. Right column shows the probability distributions of the annual posterior flux estimates for experiments E17, E18 (blue) and E21 (red). The numerical values of the prior flux, annual target flux, posterior 
Geosci. Model Dev. Discuss., doi:10.5194/gmd-2016-213, 2016

Manuscript under review for journal Geosci. Model Dev.

Published: 8 November 2016

(c) Author(s) 2016. CC-BY 3.0 License.

1185 estimates of E17, E18 and E21 are shown as vertical bars. The top (a), middle (b) and bottom 1186 panels (c) show the results for the provinces of $\mathrm{AB}, \mathrm{SK}$ and $\mathrm{ON}$ respectively.

Figure 8. 2009 annual mean spatial distributions of the fluxes at $1^{\circ} \times 1^{\circ}$ over $\mathrm{AB}+\mathrm{SK}$ (a) the target CT2011 fossil fuel $\mathrm{CO}_{2}$, (b) the CT2010 fossil fuel $\mathrm{CO}_{2}$, (c) the CT- $\mathrm{CH}_{4}$ anthropogenic $\mathrm{CH}_{4}$, and (d) the $\mathrm{CT}-\mathrm{CH}_{4}$ anthropogenic $\mathrm{CH}_{4}$ scaled to $50 \%$ of $\mathrm{CT} 2011$ fossil fuel $\mathrm{CO}_{2}$ provincial totals as the new prior.

Figure 9. Comparison of the annual estimation errors using anthropogenic $\mathrm{CH}_{4}$ (Fig. 8d) as the new prior using a normal probability density function (PDF) versus a truncated normal PDF for the simulations of the prior scaling factors.

Figure 10. Annual estimation errors using different combinations of stations for $\mathrm{AB}+\mathrm{SK}$ (a) and ON (b). One station was excluded from the standard setup in each experiment. Dashed lines show 1200 the estimation errors using all four stations for $\mathrm{AB}+\mathrm{SK}$ and all three stations for $\mathrm{ON}$. 
Geosci. Model Dev. Discuss., doi:10.5194/gmd-2016-213, 2016

Manuscript under review for journal Geosci. Model Dev.

Published: 8 November 2016

(c) Author(s) 2016. CC-BY 3.0 License.

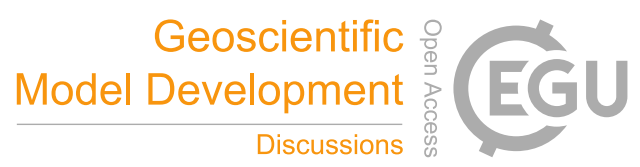

\section{Captions for tables}

1202 Table 1. Ground-based in-situ GHG measurement stations and brief descriptions for the surrounding areas.

Table 2. Provincial monthly (Mt/month) and annual (Mt/year) total fossil fuel $\mathrm{CO}_{2}$ fluxes from CT2010 and CT2011. The relative percentage differences are calculated for the monthly and annual provincial total between CT2010 and CT2011, i.e. (CT2010 - CT2011)/CT2011×100\%.

Table 3. Synthetic flux inversion experiments. Three sets of experiments were investigated (I) prior flux error only, (II) transport error only, and (III) prior flux and transport error. Common to all (prior transport model: FLEXPART, target flux: fossil fuel $\mathrm{CO}_{2} \mathrm{CT} 2011$ ). Baselines that were sampled from the CT2011 predicted fossil fuel concentration field were required for experiments E8-E21 and E29-E42. Two inversion methods were used for comparison, the Markov-Chain Monte Carlo (MCMC) simulation and cost function minimization (CFM) methods. 
Geosci. Model Dev. Discuss., doi:10.5194/gmd-2016-213, 2016

Manuscript under review for journal Geosci. Model Dev.

Published: 8 November 2016

(c) Author(s) 2016. CC-BY 3.0 License.

Table 1.

\begin{tabular}{|c|c|c|c|c|}
\hline $\begin{array}{l}\text { Station Name, } \\
\text { Province }\end{array}$ & Latitude, Longitude & $\begin{array}{l}\text { Elevation } \\
\text { (a.s.l., metres) }\end{array}$ & $\begin{array}{l}\text { Intake Height } \\
\text { (a.g.l., metres) }\end{array}$ & Brief Description \\
\hline $\begin{array}{l}\text { Lac La Biche (LLB), } \\
A B\end{array}$ & $54^{\circ} 57^{\prime} \mathrm{N}, 112^{\circ} 27^{\prime} \mathrm{W}$ & 540 & $\begin{array}{l}10(50 \text { started in } \\
\text { June 2009) }\end{array}$ & Wetland region. \\
\hline $\begin{array}{l}\text { Esther (EST), } \\
\mathrm{AB}\end{array}$ & $51^{\circ} 40^{\prime} \mathrm{N}, 110^{\circ} 12^{\prime} \mathrm{W}$ & 707 & $\begin{array}{l}3(50 \text { started in } \\
\text { March 2011) }\end{array}$ & Rural prairies. \\
\hline $\begin{array}{l}\text { East Trout Lake (ETL), } \\
\text { SK }\end{array}$ & $54^{\circ} 21^{\prime} \mathrm{N}, 104^{\circ} 59^{\prime} \mathrm{W}$ & 493 & 105 & $\begin{array}{l}\text { Southern boreal } \\
\text { forest of Canada. }\end{array}$ \\
\hline $\begin{array}{l}\text { Bratt's Lake (BRA), } \\
\text { SK }\end{array}$ & $51^{\circ} 12^{\prime} \mathrm{N}, 104^{\circ} 42^{\prime} \mathrm{W}$ & 595 & 35 & Rural prairies. \\
\hline $\begin{array}{l}\text { Fraserdale (FRD), } \\
\text { ON }\end{array}$ & $49^{\circ} 53^{\prime} \mathrm{N}, 81^{\circ} 34^{\prime} \mathrm{W}$ & 210 & 40 & $\begin{array}{l}\text { Between south of the } \\
\text { Hudson Bay Lowland } \\
\text { and boreal forest } \\
\text { region. }\end{array}$ \\
\hline $\begin{array}{l}\text { Egbert (EGB), } \\
\text { ON }\end{array}$ & $44^{\circ} 14^{\prime} \mathrm{N}, 79^{\circ} 47^{\prime} \mathrm{W}$ & 251 & $\begin{array}{l}3 \text { (25 started in } \\
\text { March 2009) }\end{array}$ & Rural. \\
\hline $\begin{array}{l}\text { Downsview (DOW), } \\
\text { ON }\end{array}$ & $43^{\circ} 47^{\prime} \mathrm{N}, 79^{\circ} 28^{\prime} \mathrm{W}$ & 198 & 20 & Suburban. \\
\hline
\end{tabular}

Table 2.

\begin{tabular}{llrrrrrrrrrrrrr}
\hline Release & Prov. & \multicolumn{1}{c}{ Jan } & \multicolumn{1}{c}{ Feb } & \multicolumn{1}{c}{ Mar } & \multicolumn{1}{c}{ Apr } & \multicolumn{1}{c}{ May } & \multicolumn{1}{l}{ Jun } & \multicolumn{1}{l}{ Jul } & \multicolumn{1}{c}{ Aug } & \multicolumn{1}{l}{ Sep } & \multicolumn{1}{l}{ Oct } & \multicolumn{1}{l}{ Nov } & Dec & Y2009 \\
\hline CT2010 & AB & 9.4 & 8.6 & 8.2 & 7.8 & 7.2 & 7.5 & 8 & 7.8 & 7.4 & 7.3 & 7.7 & 8.7 & 95.6 \\
CT2010 & SK & 2.5 & 2.3 & 2.2 & 2.1 & 1.9 & 2 & 2.1 & 2.1 & 2 & 2 & 2.1 & 2.4 & 25.7 \\
CT2010 & AB+SK & 11.9 & 10.9 & 10.4 & 9.9 & 9.1 & 9.5 & 10.1 & 9.9 & 9.4 & 9.3 & 9.8 & 11.1 & 121.3 \\
CT2010 & ON & 15 & 13.8 & 13.2 & 12.5 & 11.6 & 12 & 12.8 & 12.5 & 11.9 & 11.7 & 12.4 & 14.1 & 153.5 \\
& & & & & & & & & & & & & & \\
CT2011 & AB & 12.4 & 12.1 & 11.2 & 10.3 & 9.6 & 9.7 & 9.9 & 10 & 9.8 & 10.1 & 10.9 & 11.9 & 127.9 \\
CT2011 & SK & 3.3 & 3.3 & 3 & 2.8 & 2.6 & 2.6 & 2.7 & 2.7 & 2.7 & 2.7 & 2.9 & 3.2 & 34.5 \\
CT2011 & AB+SK & 15.7 & 15.4 & 14.2 & 13.1 & 12.2 & 12.3 & 12.6 & 12.7 & 12.5 & 12.8 & 13.8 & 15.1 & 162.4 \\
CT2011 & ON & 13.2 & 12.6 & 11.8 & 11.1 & 10.4 & 10.7 & 11.1 & 11 & 10.7 & 10.8 & 11.5 & 12.6 & 137.5 \\
& & & & & & & & & & & & & & \\
CT2010-CT2011 & AB & -24 & -29 & -27 & -24 & -25 & -23 & -19 & -22 & -24 & -28 & -29 & -27 & -25 \\
CT2011 & SK & -24 & -30 & -27 & -25 & -27 & -23 & -22 & -22 & -26 & -26 & -28 & -25 & -26 \\
& AB+SK & -24 & -29 & -27 & -24 & -25 & -23 & -20 & -22 & -25 & -27 & -29 & -26 & -25 \\
& ON & 14 & 10 & 12 & 13 & 12 & 12 & 15 & 14 & 11 & 8 & 8 & 12 & 12
\end{tabular}


Geosci. Model Dev. Discuss., doi:10.5194/gmd-2016-213, 2016

Manuscript under review for journal Geosci. Model Dev.

Published: 8 November 2016

(c) Author(s) 2016. CC-BY 3.0 License.

\section{(c) (i)}

Table 3a.

\begin{tabular}{|c|c|c|c|c|c|}
\hline Experiment & $\begin{array}{l}\text { Inversion } \\
\text { method }\end{array}$ & $\begin{array}{l}\text { Number of sub- } \\
\text { regions }\end{array}$ & $\begin{array}{l}\left(\sigma_{e}\right)^{2},\left(\sigma_{\text {prior }}\right)^{2} \\
\text { in } \%\end{array}$ & $\begin{array}{l}\text { Prior } \\
\text { flux }\end{array}$ & $\begin{array}{l}\text { Synthetic obs } \\
\text { simulated by }\end{array}$ \\
\hline E1/E22 & MCMC/CFM & $\mathrm{AB}+\mathrm{SK}: 2, \mathrm{ON}: 1$ & 30,100 & CT2010 & $\begin{array}{l}\text { CT2011 flux in } \\
\text { FLEXPART }\end{array}$ \\
\hline E2/E23 & МCMC/CFM & $\mathrm{AB}+\mathrm{SK}: 4, \mathrm{ON}: 2$ & 30,100 & СТ2010 & $\begin{array}{l}\text { CT2011 flux in } \\
\text { FLEXPART }\end{array}$ \\
\hline E3/E24 & MCMC/CFM & $\mathrm{AB}+\mathrm{SK}: 7, \mathrm{ON}: 4$ & 30,100 & CT2010 & $\begin{array}{l}\text { CT2011 flux in } \\
\text { FLEXPART }\end{array}$ \\
\hline E4/E25 & МCMC/CFM & $\mathrm{AB}+\mathrm{SK}: 11, \mathrm{ON}: 6$ & 30,100 & CT2010 & $\begin{array}{l}\text { CT2011 flux in } \\
\text { FLEXPART }\end{array}$ \\
\hline E5/E26 & МCMC/CFM & $\mathrm{AB}+\mathrm{SK}: 19, \mathrm{ON}: 12$ & 30,100 & CT2010 & $\begin{array}{l}\text { CT2011 flux in } \\
\text { FLEXPART }\end{array}$ \\
\hline E6/E27 & МCMC/CFM & $\mathrm{AB}+\mathrm{SK}: 27, \mathrm{ON}: 24$ & 30,100 & CT2010 & $\begin{array}{l}\text { CT2011 flux in } \\
\text { FLEXPART }\end{array}$ \\
\hline E7/E28 & MCMC/CFM & $\mathrm{AB}+\mathrm{SK}: 37, \mathrm{ON}: 49$ & 30,100 & СТ2010 & $\begin{array}{l}\text { CT2011 flux in } \\
\text { FLEXPART }\end{array}$ \\
\hline
\end{tabular}

Table 3b.

\begin{tabular}{|c|c|c|c|c|c|}
\hline Experiment & $\begin{array}{l}\text { Inversion } \\
\text { method }\end{array}$ & $\begin{array}{l}\text { Number of sub- } \\
\text { regions }\end{array}$ & $\begin{array}{l}\left(\sigma_{e}\right)^{2},\left(\sigma_{\text {prior }}\right)^{2} \\
\text { in } \%\end{array}$ & $\begin{array}{l}\text { Prior } \\
\text { flux }\end{array}$ & $\begin{array}{l}\text { Synthetic obs } \\
\text { simulated by }\end{array}$ \\
\hline E8/E29 & МCMC/CFM & $\mathrm{AB}+\mathrm{SK}: 2, \mathrm{ON}: 1$ & 30,100 & CT2011 & $\begin{array}{l}\text { CT2011 flux in } \\
\text { CT2011 }\end{array}$ \\
\hline E9/E30 & MCMC/CFM & $\mathrm{AB}+\mathrm{SK}: 4, \mathrm{ON}: 2$ & 30,100 & СТ2011 & $\begin{array}{l}\text { CT2011 flux in } \\
\text { CT2011 }\end{array}$ \\
\hline E10/E31 & МCMC/CFM & $\mathrm{AB}+\mathrm{SK}: 7, \mathrm{ON}: 4$ & 30,100 & СТ2011 & $\begin{array}{l}\text { CT2011 flux in } \\
\text { CT2011 }\end{array}$ \\
\hline E11/E32 & MCMC/CFM & $\mathrm{AB}+\mathrm{SK}: 11, \mathrm{ON}: 6$ & 30,100 & CT2011 & $\begin{array}{l}\text { CT2011 flux in } \\
\text { CT2011 }\end{array}$ \\
\hline E12/E33 & MCMC/CFM & $\mathrm{AB}+\mathrm{SK}: 19, \mathrm{ON}: 12$ & 30,100 & СТ2011 & $\begin{array}{l}\text { CT2011 flux in } \\
\text { CT2011 }\end{array}$ \\
\hline E13/E34 & MCMC/CFM & $\mathrm{AB}+\mathrm{SK}: 27, \mathrm{ON}: 24$ & 30,100 & СТ2011 & $\begin{array}{l}\text { CT2011 flux in } \\
\text { CT2011 }\end{array}$ \\
\hline E14/E35 & МCMC/CFM & $\mathrm{AB}+\mathrm{SK}: 37, \mathrm{ON}: 49$ & 30,100 & CT2011 & $\begin{array}{l}\text { CT2011 flux in } \\
\text { CT2011 }\end{array}$ \\
\hline
\end{tabular}


Geosci. Model Dev. Discuss., doi:10.5194/gmd-2016-213, 2016

Manuscript under review for journal Geosci. Model Dev.

Published: 8 November 2016

(c) Author(s) 2016. CC-BY 3.0 License.

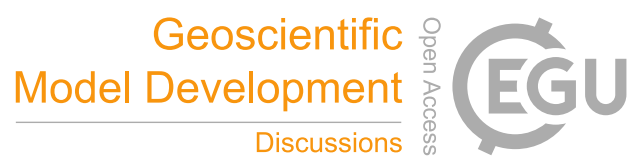

(c) (1)

Table 3c.

\begin{tabular}{llllll} 
Experiment & $\begin{array}{l}\text { Inversion } \\
\text { method }\end{array}$ & $\begin{array}{l}\text { Number of sub- } \\
\text { regions }\end{array}$ & $\begin{array}{l}\left(\sigma_{e}\right)^{2},\left(\sigma_{\text {prior }}\right)^{2} \\
\text { in \% }\end{array}$ & $\begin{array}{l}\text { Prior } \\
\text { flux }\end{array}$ & $\begin{array}{l}\text { Synthetic obs } \\
\text { simulated by }\end{array}$ \\
\hline E15/E36 & MCMC/CFM & AB+SK:2, ON:1 & 30,100 & CT2010 & $\begin{array}{l}\text { CT2011 flux in } \\
\text { CT2011 } \\
\text { CT2011 flux in }\end{array}$ \\
E16/E37 & MCMC/CFM & AB+SK:4, ON:2 & 30,100 & CT2010 & $\begin{array}{l}\text { CT2011 } \\
\text { CT2011 flux in }\end{array}$ \\
E17/E38 & MCMC/CFM & AB+SK:7, ON:4 & 30,100 & CT2010 & $\begin{array}{l}\text { CT2011 } \\
\text { CT }\end{array}$ \\
E18/E39 & MCMC/CFM & AB+SK:11, ON:6 & 30,100 & CT2010 & $\begin{array}{l}\text { CT2011 flux in } \\
\text { CT2011 }\end{array}$ \\
E19/E40 & MCMC/CFM & AB+SK:19, ON:12 & 30,100 & CT2010 & $\begin{array}{l}\text { CT2011 flux in } \\
\text { CT2011 }\end{array}$ \\
E20/E41 & MCMC/CFM & AB+SK:27, ON:24 & 30,100 & CT2010 & $\begin{array}{l}\text { CT2011 flux in } \\
\text { CT2011 }\end{array}$ \\
E21/E42 & MCMC/CFM & AB+SK:37, ON:49 & 30,100 & CT2010 & $\begin{array}{l}\text { CT2011 flux in } \\
\text { CT2011 }\end{array}$
\end{tabular}


Geosci. Model Dev. Discuss., doi:10.5194/gmd-2016-213, 2016

Manuscript under review for journal Geosci. Model Dev.

Published: 8 November 2016

(c) Author(s) 2016. CC-BY 3.0 License.

\section{(c) (i)}

Figure 1

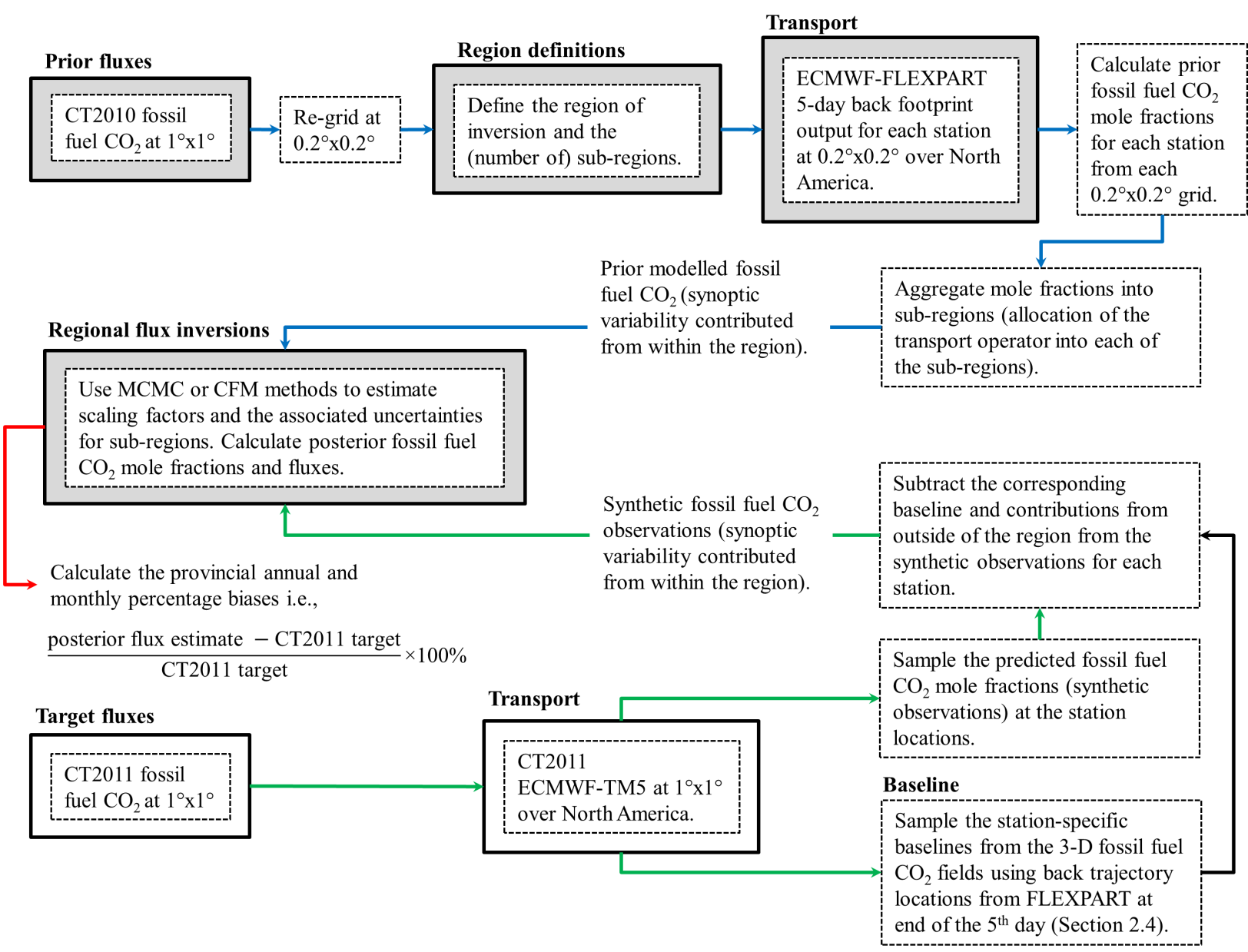


Geosci. Model Dev. Discuss., doi:10.5194/gmd-2016-213, 2016 Manuscript under review for journal Geosci. Model Dev.

Published: 8 November 2016

(c) Author(s) 2016. CC-BY 3.0 License.

Figure 2

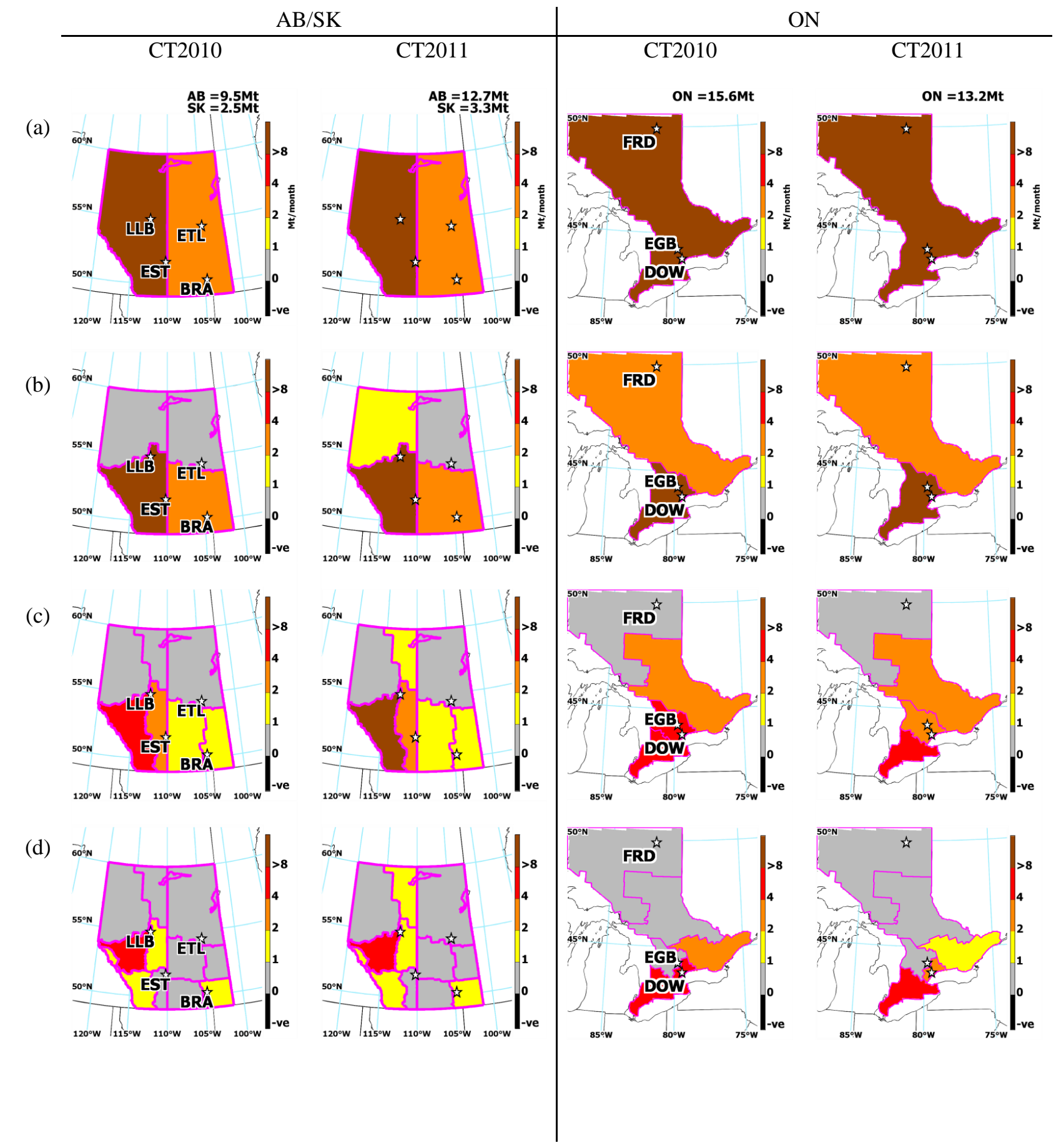


Geosci. Model Dev. Discuss., doi:10.5194/gmd-2016-213, 2016 Manuscript under review for journal Geosci. Model Dev.

Published: 8 November 2016

(c) Author(s) 2016. CC-BY 3.0 License.

\section{Geoscientific \\ Model Development \\ Discussions}

(c) $\underset{\mathrm{Br}}{(\mathrm{i})}$

Figure 2

(e)

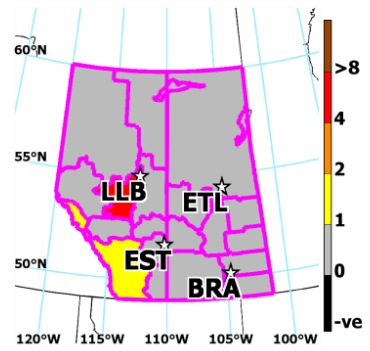

(f)

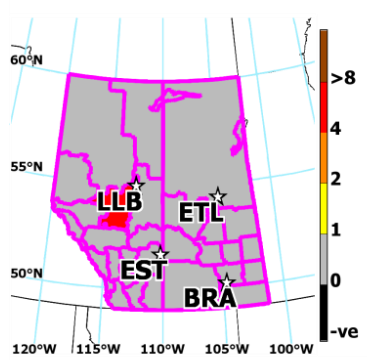

(g)

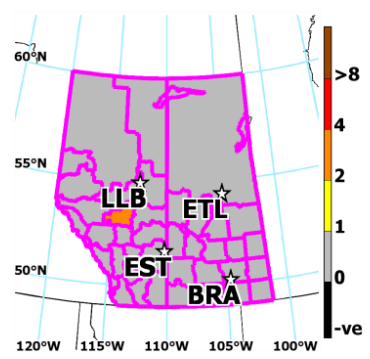

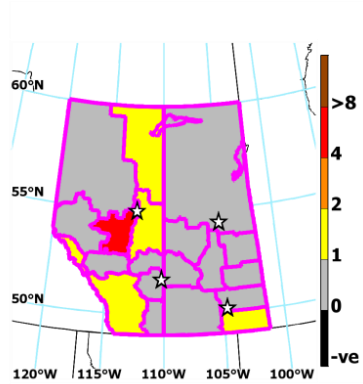
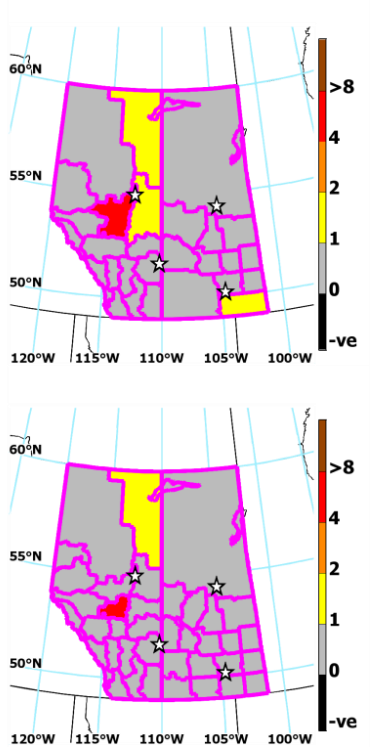
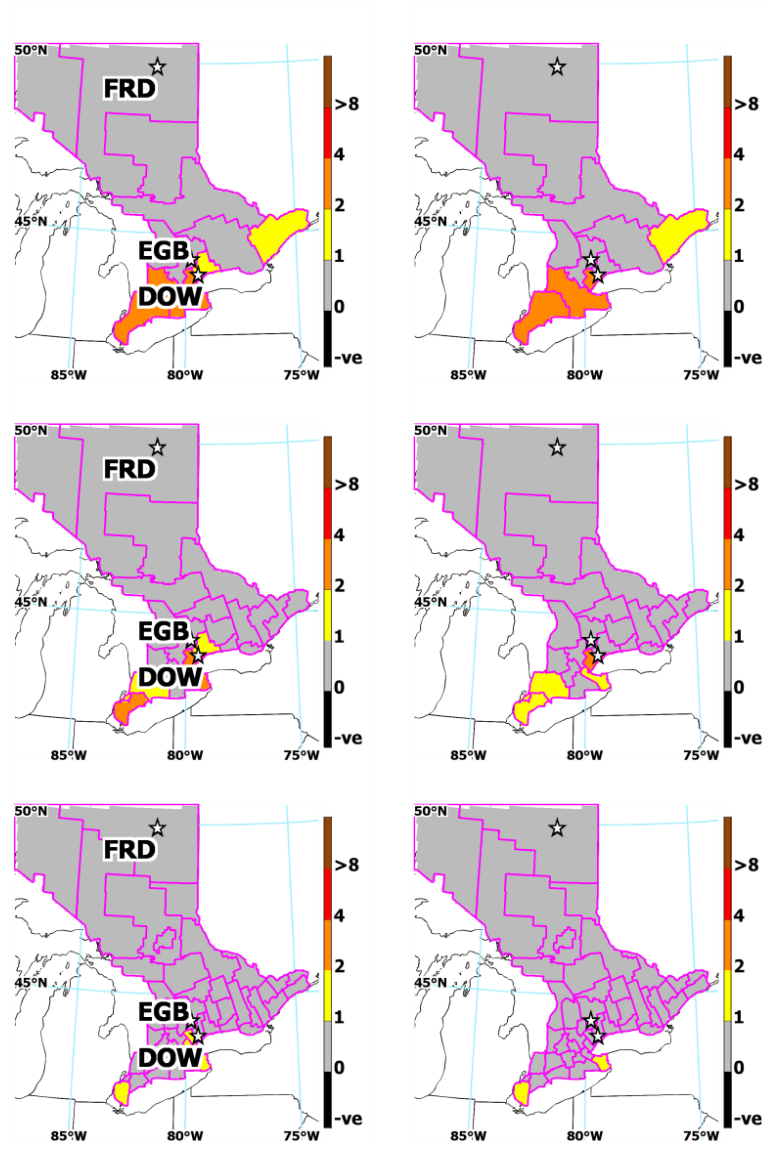
Geosci. Model Dev. Discuss., doi:10.5194/gmd-2016-213, 2016 Manuscript under review for journal Geosci. Model Dev.

Published: 8 November 2016

(c) Author(s) 2016. CC-BY 3.0 License.

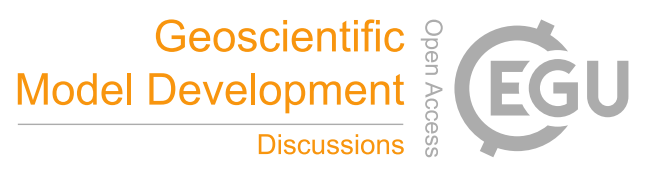

(c)

Figure 3

\section{Max Value: 5677 ps/ kg \\ Mean Value: 64 ps/kg}

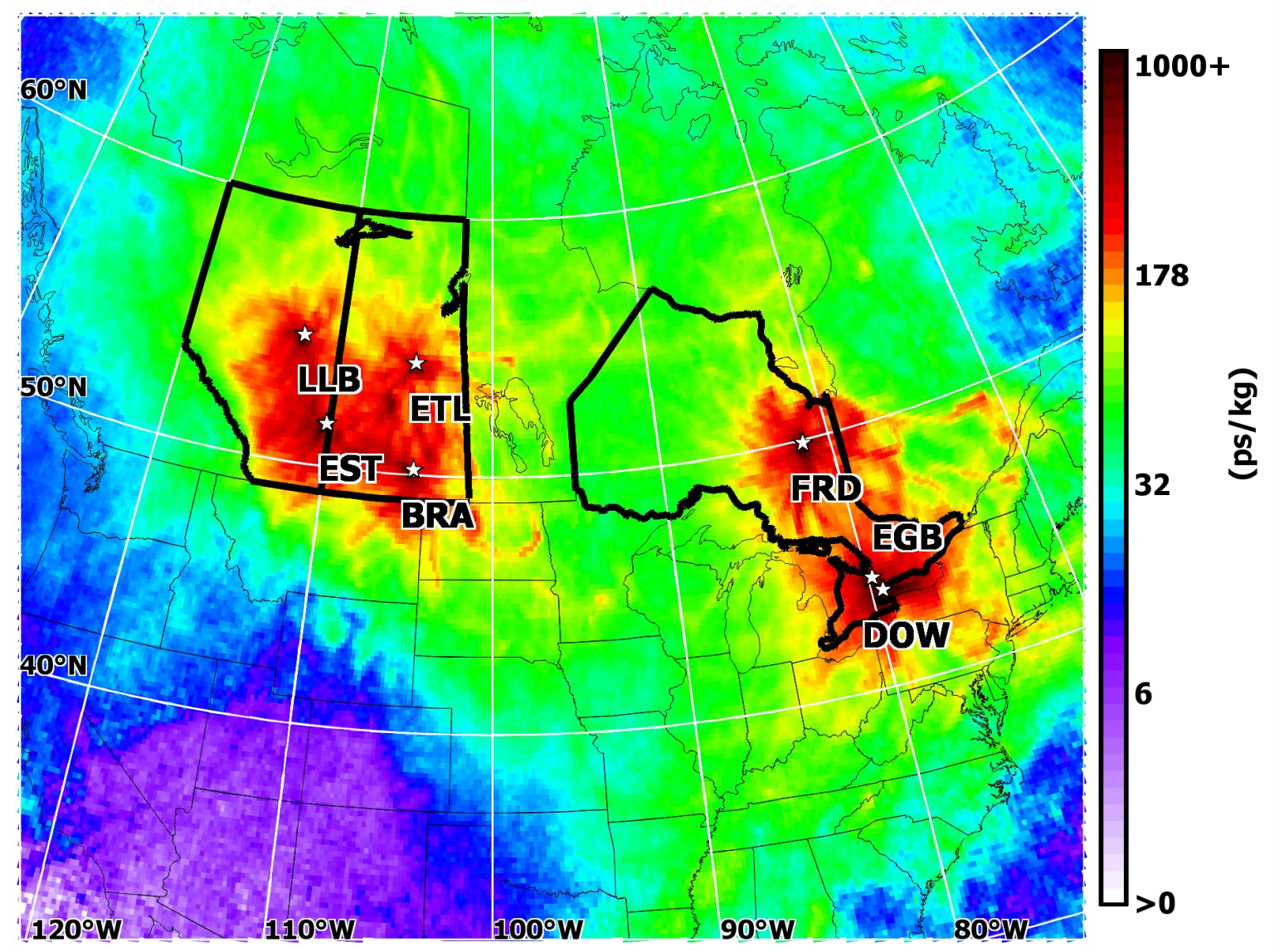


Geosci. Model Dev. Discuss., doi:10.5194/gmd-2016-213, 2016 Manuscript under review for journal Geosci. Model Dev.

Published: 8 November 2016

(c) Author(s) 2016. CC-BY 3.0 License.

(c) (1)

Figure 4

(a)
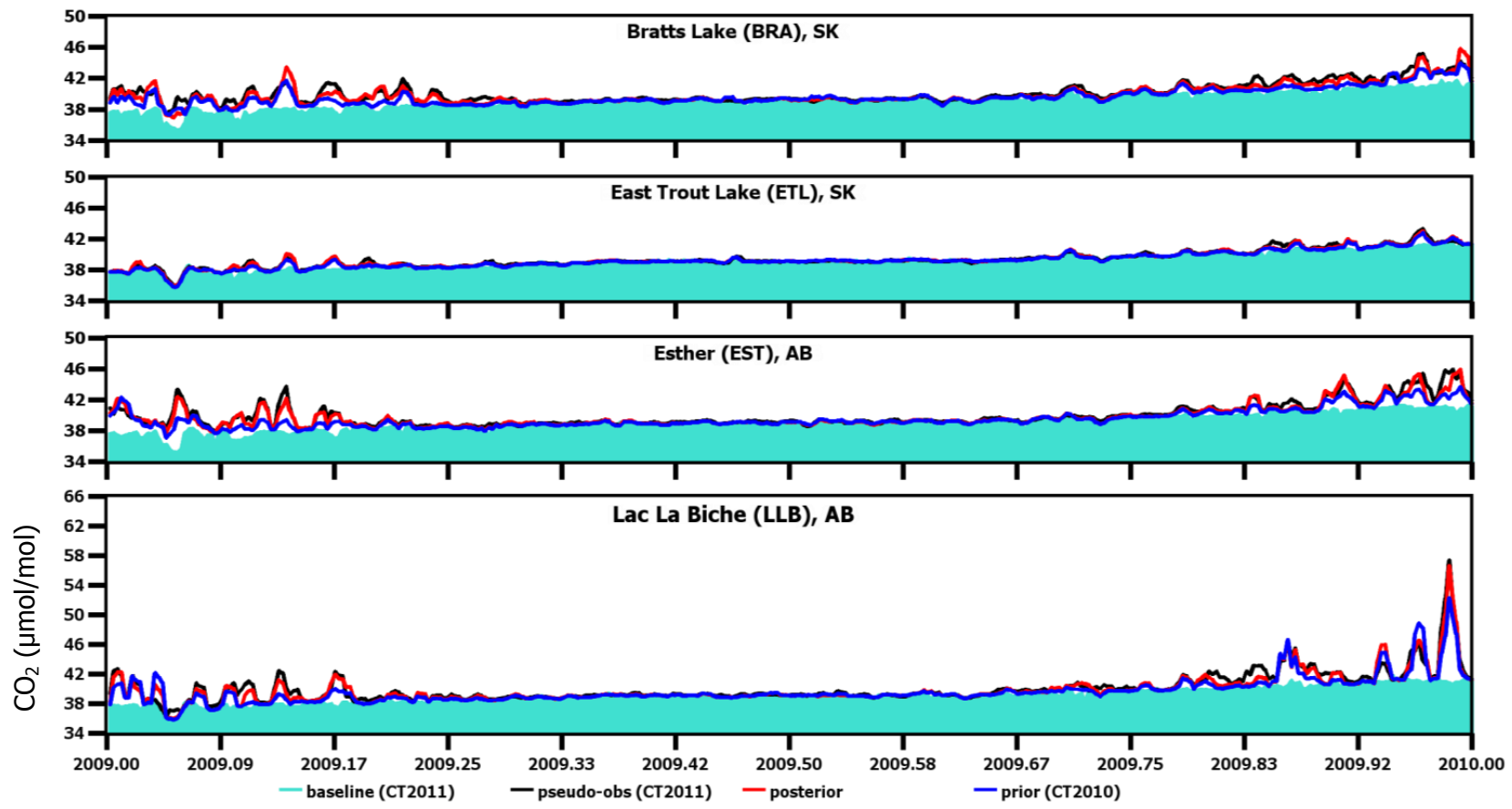
Geosci. Model Dev. Discuss., doi:10.5194/gmd-2016-213, 2016 Manuscript under review for journal Geosci. Model Dev.

Published: 8 November 2016

(c) Author(s) 2016. CC-BY 3.0 License.

\section{(c) (i)}

Figure 4

(b)
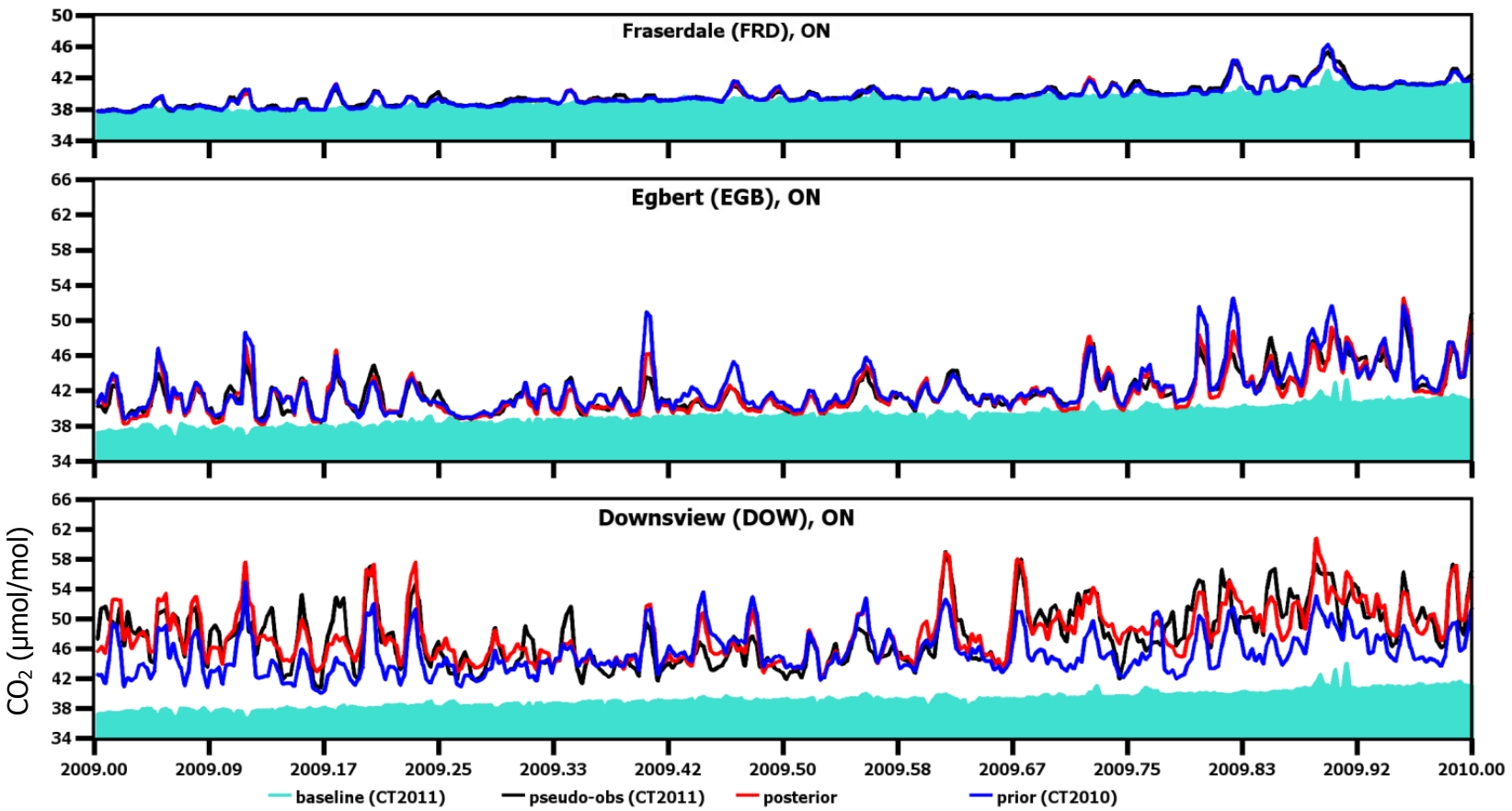
Geosci. Model Dev. Discuss., doi:10.5194/gmd-2016-213, 2016

Manuscript under review for journal Geosci. Model Dev.

Published: 8 November 2016

(c) Author(s) 2016. CC-BY 3.0 License.

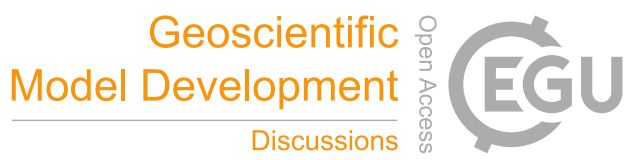

(c) (i)

Figure 5

(a)

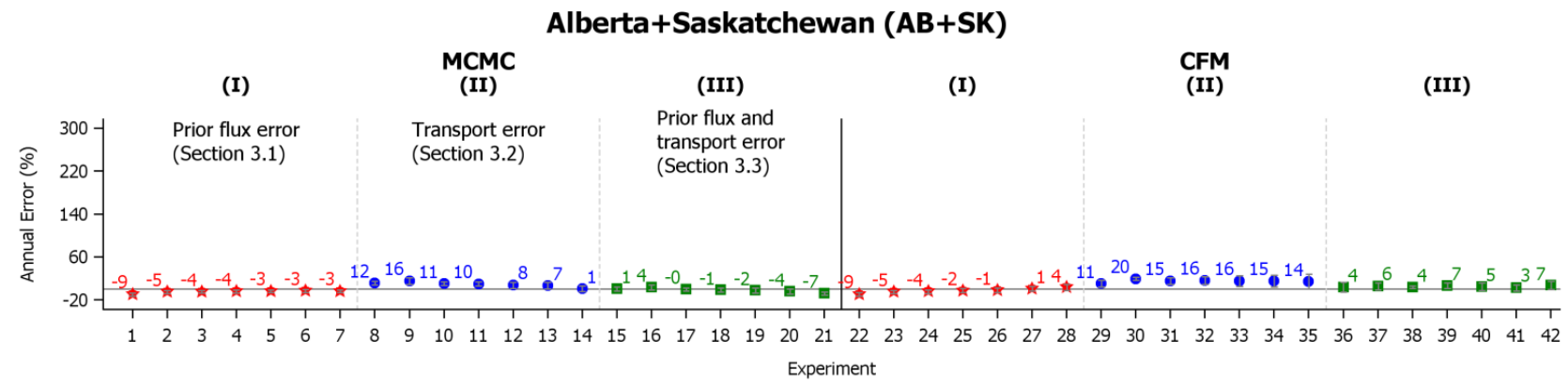

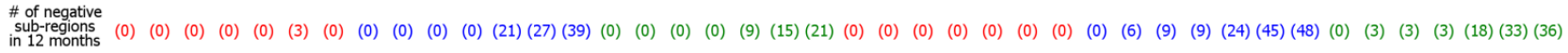
\# of sub-regions (2) (4) (7) (11) (19) (27) (37) (2) (4) (7) (11) (19) (27) (37) (2) (4) (7) (11) (19) (27) (37) (2) (4) (7) (11) (19) (27) (37) (2) (4) (7) (11) (19) (27) (37) (2) (4) (7) (11) (19) (27) (37)

(b)

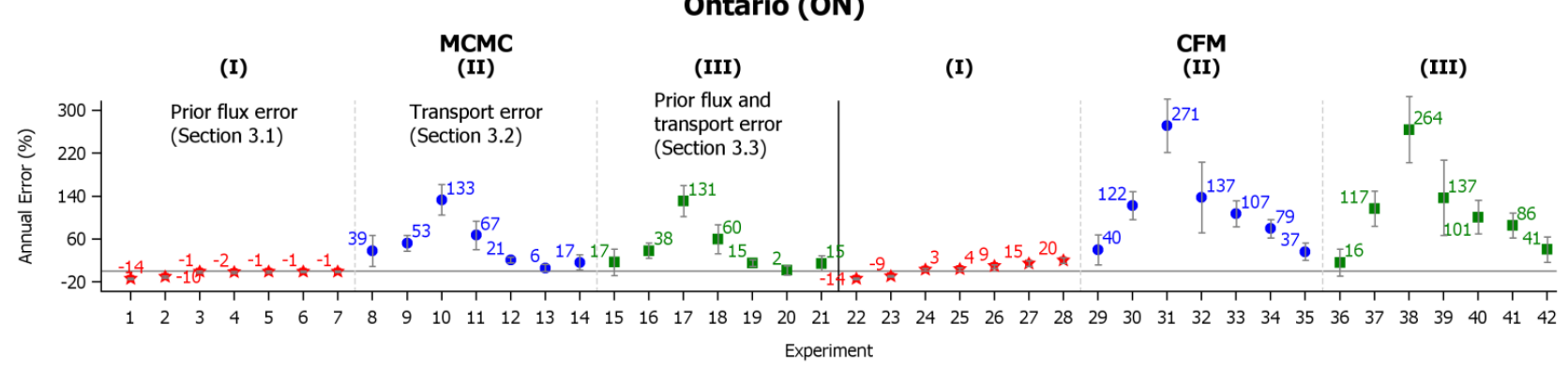

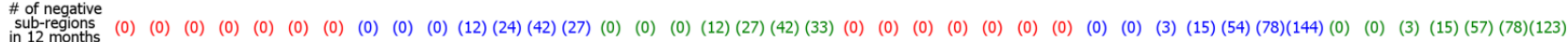
\# of sub-regions(1) (2) (4) (6) (12) (23) (49) (1) (2) (4) (6) (12) (23) (49) (1) (2) (4) (6) (12) (23) (49) (1) (2) (4) (6) (12) (23) (49) (1) (2) (4) (6) (12) (23) (49) (1) (2) (4) (6) (12) (23) (49) 
Geosci. Model Dev. Discuss., doi:10.5194/gmd-2016-213, 2016 Manuscript under review for journal Geosci. Model Dev.

Published: 8 November 2016

(c) Author(s) 2016. CC-BY 3.0 License.

(c) (i)

Figure 6

(a)

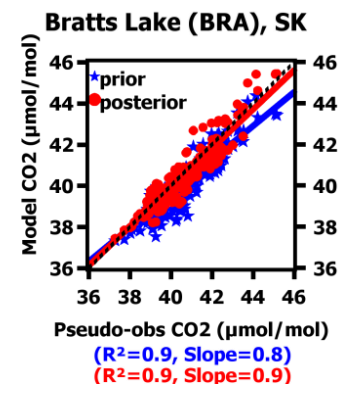

(b)

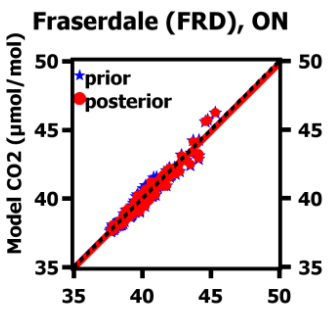

Pseudo-obs $\mathrm{CO2}(\mu \mathrm{mol} / \mathrm{mol})$ $\left(R^{2}=1\right.$, Slope $\left.=1\right)$
$\left(R^{2}=1\right.$, Slope $\left.=1\right)$
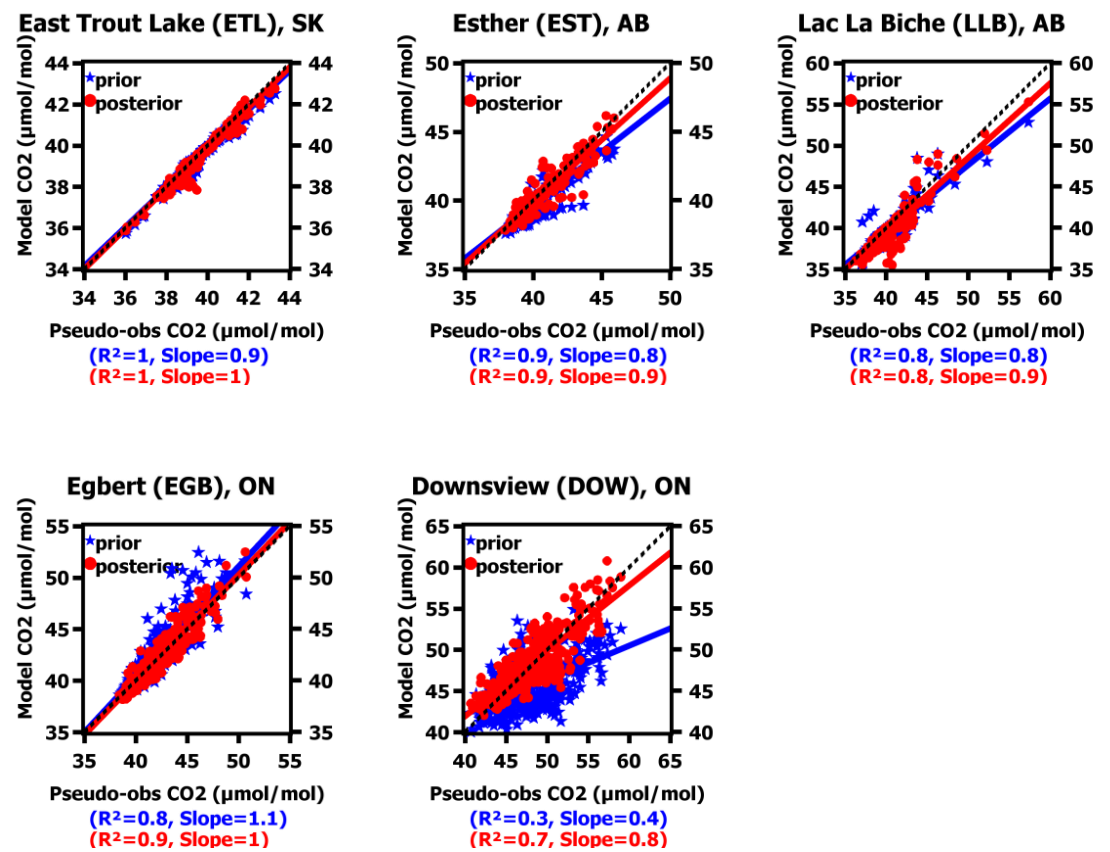
Geosci. Model Dev. Discuss., doi:10.5194/gmd-2016-213, 2016

Manuscript under review for journal Geosci. Model Dev.

Published: 8 November 2016

(c) Author(s) 2016. CC-BY 3.0 License.
Figure 7

(a)

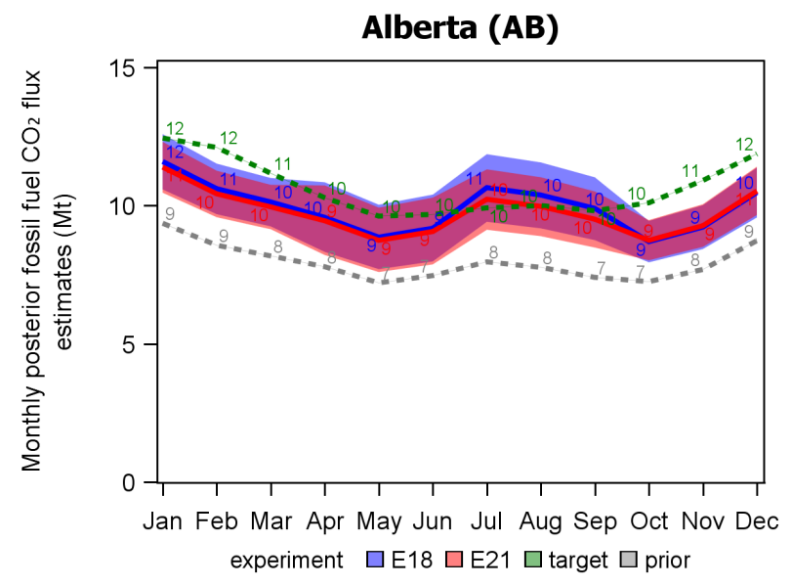

(b)

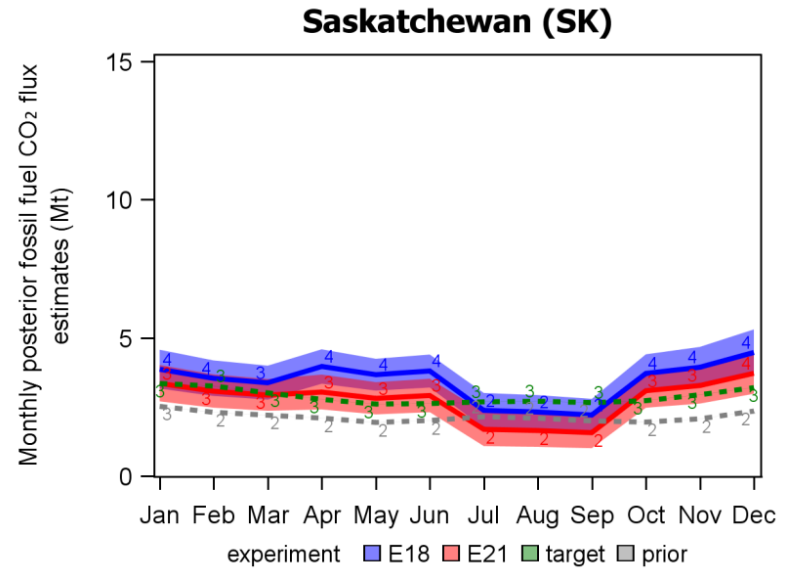

(c)

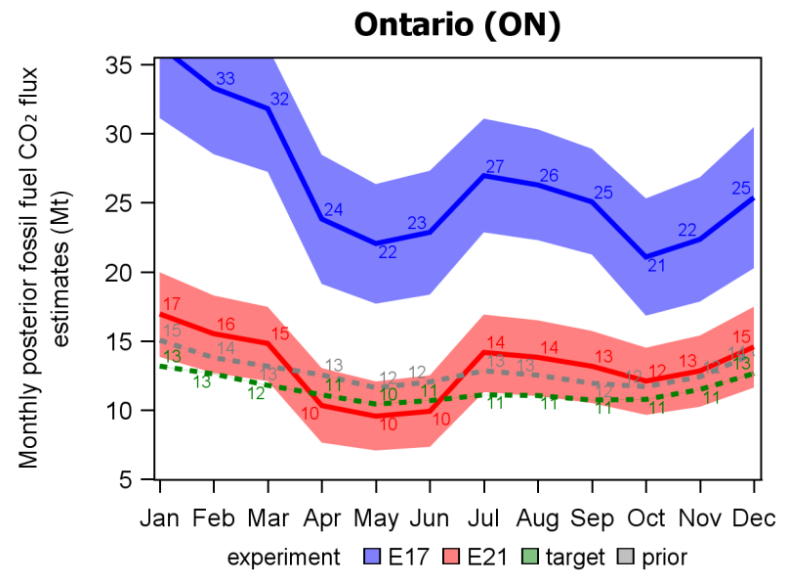

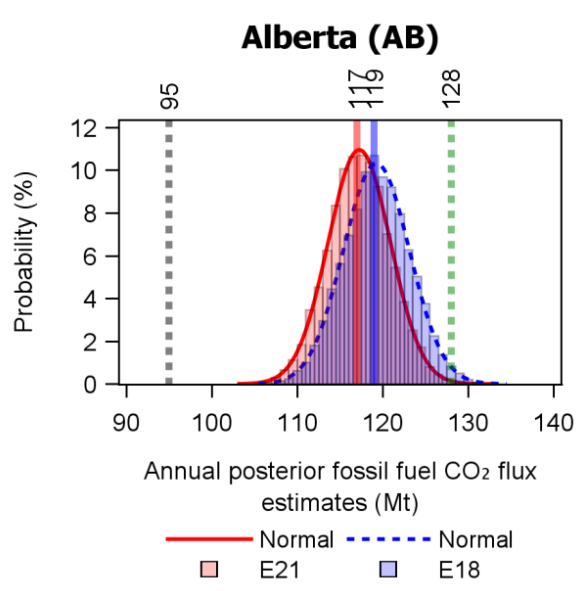
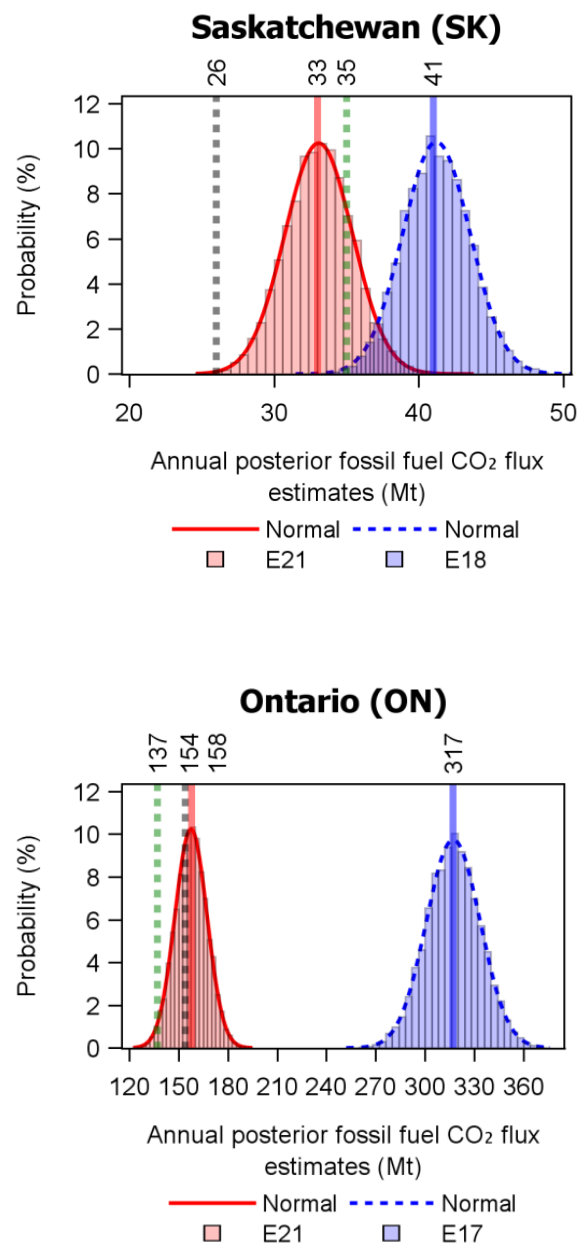
Geosci. Model Dev. Discuss., doi:10.5194/gmd-2016-213, 2016 Manuscript under review for journal Geosci. Model Dev.

Published: 8 November 2016

(c) Author(s) 2016. CC-BY 3.0 License.

\section{(c) (1)}

Figure 8

(a)

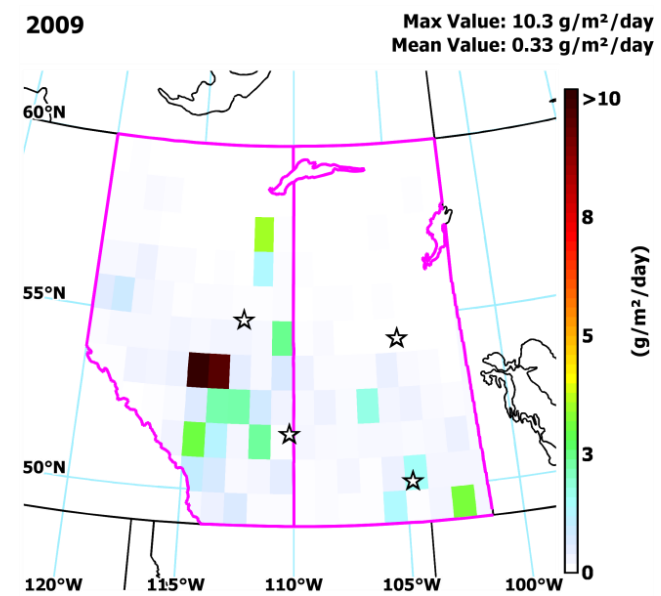

(c)

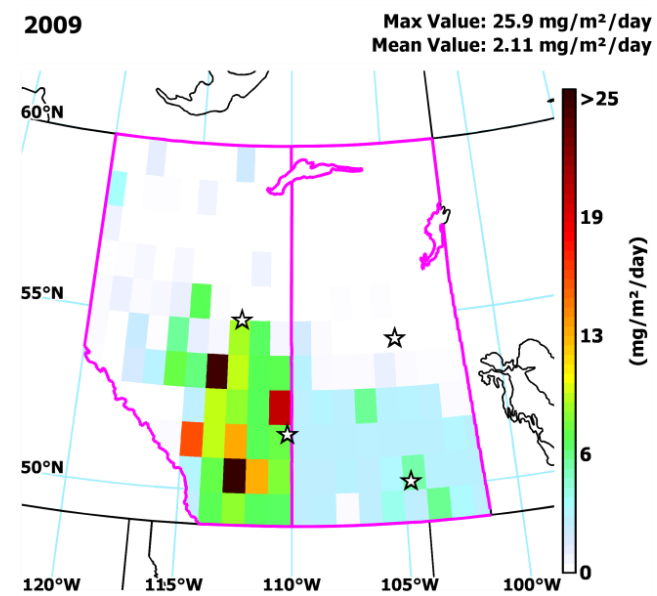

(b)

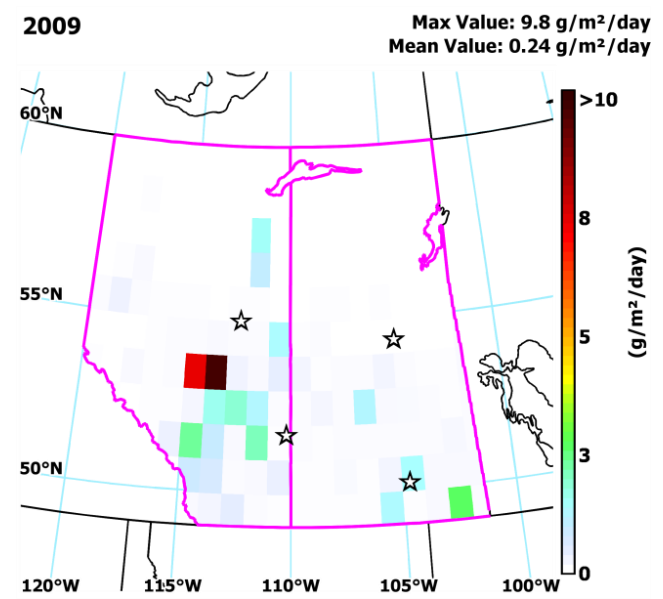

(d)

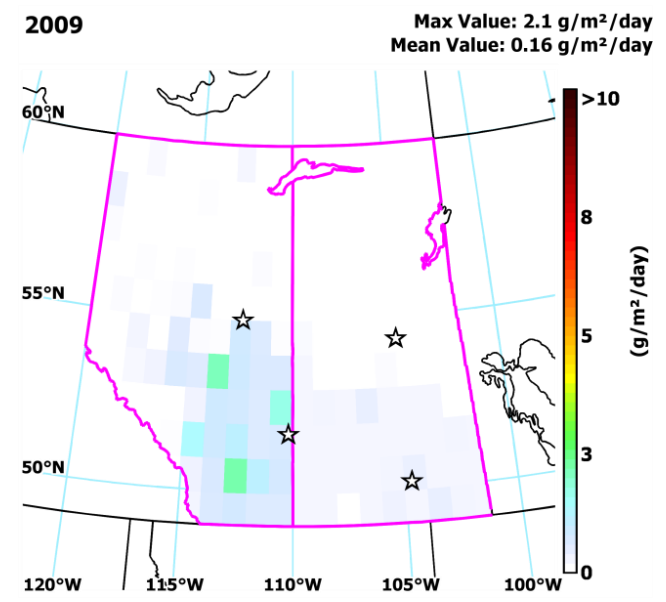


Geosci. Model Dev. Discuss., doi:10.5194/gmd-2016-213, 2016

Manuscript under review for journal Geosci. Model Dev.

Published: 8 November 2016

(c) Author(s) 2016. CC-BY 3.0 License.

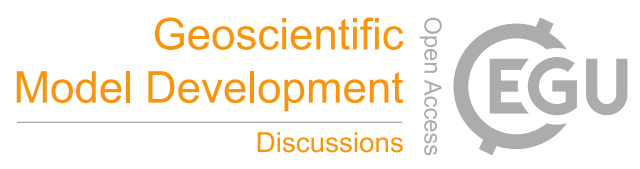

(c) (i)

Figure 9

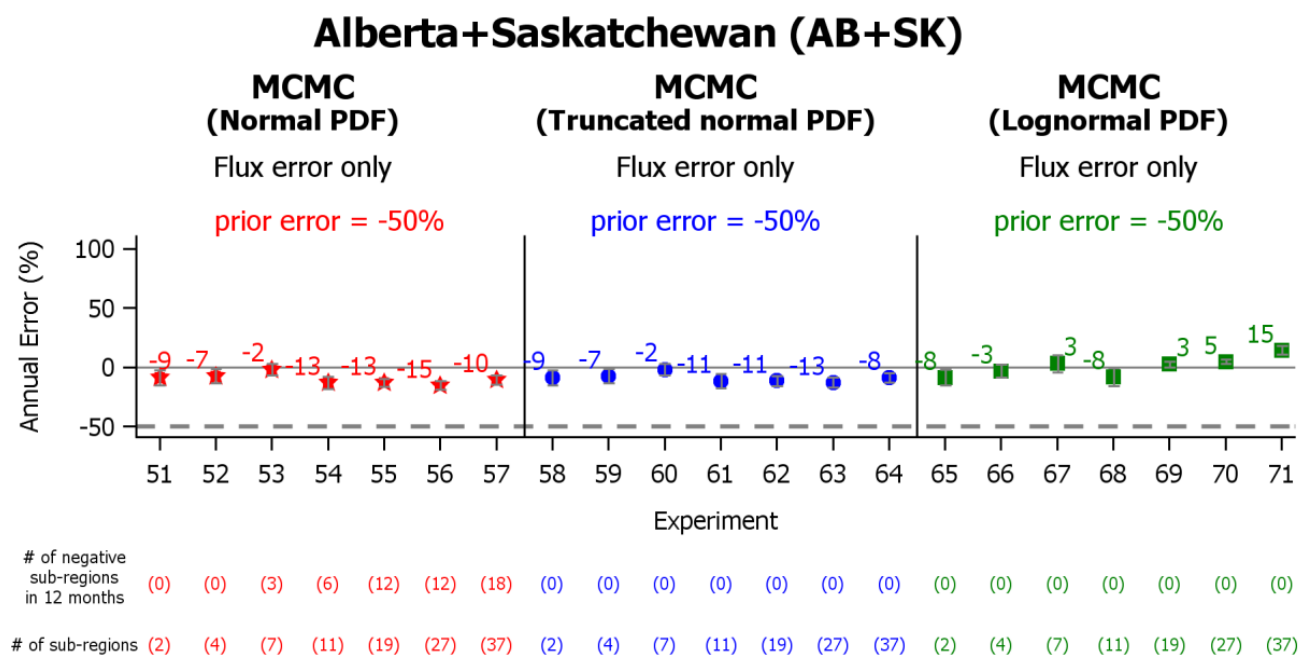


Geosci. Model Dev. Discuss., doi:10.5194/gmd-2016-213, 2016

Manuscript under review for journal Geosci. Model Dev.

Published: 8 November 2016

(c) Author(s) 2016. CC-BY 3.0 License.

(c) (1)

Figure 10

(a)

\section{Alberta+Saskatchewan (AB+SK) MCMC \\ (II) \\ (II)}

Transport error

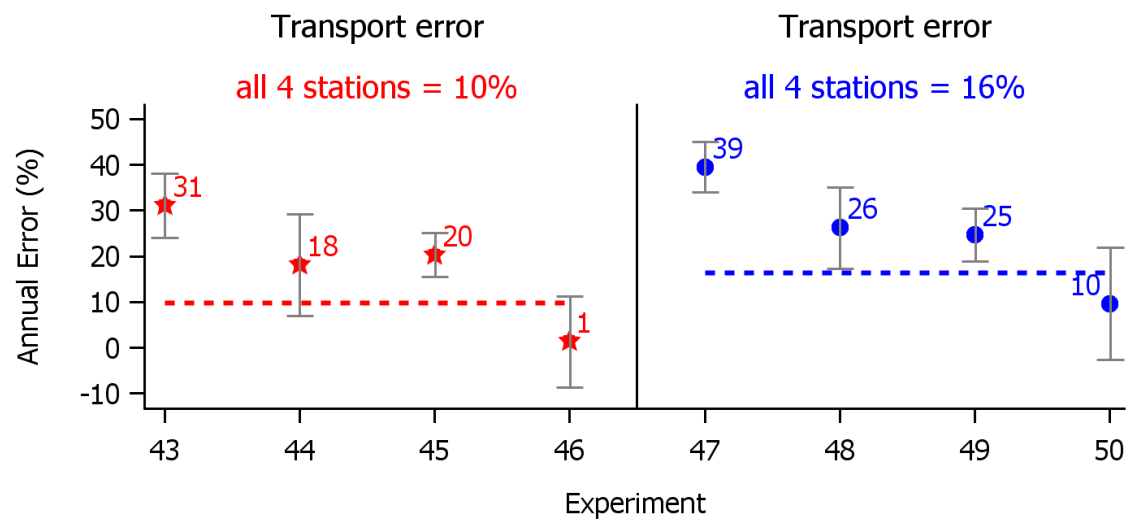

Stations (LLB,ETL,BRA) (LLB,ETL,EST) (LLB,EST,BRA) (BRA,ETL,EST) (LLB,ETL,BRA) (LLB,ETL,EST) (LLB,EST,BRA) (BRA,ETL,EST)

(b)

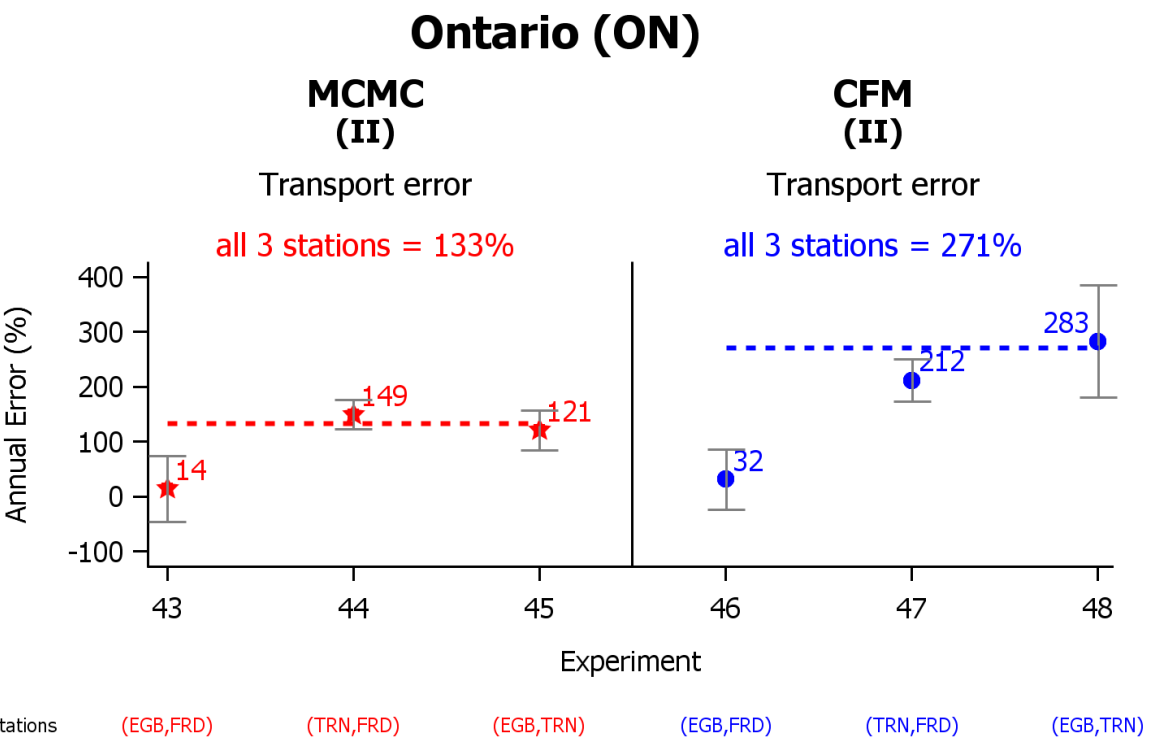

